\title{
Variation in plastid genomes in the gynodioecious species Silene vulgaris
}

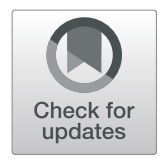

Manuela Krüger, Oushadee A. J. Abeyawardana, Miloslav Juříček, Claudia Krüger and Helena Štorchová* (D)

\begin{abstract}
Background: Gynodioecious species exist in two sexes - male-sterile females and hermaphrodites. Male sterility in higher plants often results from mitonuclear interaction between the CMS (cytoplasmic male sterility) gene(s) encoded by mitochondrial genome and by nuclear-encoded restorer genes. Mitochondrial and nuclear-encoded transcriptomes in females and hermaphrodites are intensively studied, but little is known about sex-specific gene expression in plastids. We have compared plastid transcriptomes between females and hermaphrodites in two haplotypes of a gynodioecious species Silene vulgaris with known CMS candidate genes.

Results: We generated complete plastid genome sequences from five haplotypes $S$. vulgaris including the haplotypes KRA and KOV, for which complete mitochondrial genome sequences were already published. We constructed a phylogenetic tree based on plastid sequences of S. vulgaris. Whereas lowland S. vulgaris haplotypes including KRA and KOV clustered together, the accessions from high European mountains diverged early in the phylogram. S. vulgaris belongs among Silene species with slowly evolving plastid genomes, but we still detected 212 substitutions and 112 indels between two accessions of this species. We estimated elevated Ka/Ks in the ndhF gene, which may reflect the adaptation of $S$. vulgaris to high altitudes, or relaxed selection. We compared depth of coverage and editing rates between female and hermaphrodite plastid transcriptomes and found no significant differences between the two sexes. We identified 51 unique $C$ to $U$ editing sites in the plastid genomes of $S$. vulgaris, 38 of them in protein coding regions, 2 in introns, and 11 in intergenic regions. The editing site in the psbZ gene was edited only in one of two plastid genomes under study.

Conclusions: We revealed no significant differences between the sexes in plastid transcriptomes of two haplotypes of $S$. vulgaris. It suggests that gene expression of plastid genes is not affected by CMS in flower buds of S. vulgaris, although both sexes may still differ in plastid gene expression in specific tissues. We revealed the difference between the plastid transcriptomes of two S. vulgaris haplotypes in editing rate and in the coverage of several antisense transcripts. Our results document the variation in plastid genomes and transcriptomes in S. vulgaris.
\end{abstract}

\section{Background}

Gynodioecy is a plant breeding system, in which hermaphrodite $(\mathrm{H})$ and female $(\mathrm{F})$ individuals co-occur in the same population. It occurs in about $2 \%$ of all angiosperm genera [1]. Male sterility in most (but not in all) gynodioecious plant species is encoded by the interaction of mitochondrial-encoded cytoplasmic male sterility (CMS) genes and by nuclear restorer of fertility $(R f)$ genes [2]. CMS is used in agriculture to produce hybrid seed with high yield and it is therefore extensively studied in crops, e.g., rice [3, 4], sunflower [5], maize [6], or sugar beet [7].

\footnotetext{
* Correspondence: storchova@ueb.cas.cz

Plant Reproduction Laboratory, Institute of Experimental Botany v.v.i, Czech

Academy of Sciences, Rozvojová 263, 16502 Prague, Czech Republic
}

Despite a widespread occurrence of gynodioecy among angiosperms, studies of CMS in wild species remain scarce. Silene vulgaris (bladder campion) emerged as a model for the study of gynodioecy and CMS in natural populations more than two decades ago [8]. The genus Silene is rich in species with diverse mating systems hermaphroditism, gynodioecy and dioecy $[9,10]$. The mating system affects DNA sequence variation in organellar loci, which is often higher in gynodioecious Silene species than in their closely related dioecious or hermaphroditic congeners most likely owing to balancing selection acting on CMS loci and the whole organellar genome $[11,12]$.

(c) The Author(s). 2019 Open Access This article is distributed under the terms of the Creative Commons Attribution 4.0 International License (http://creativecommons.org/licenses/by/4.0/), which permits unrestricted use, distribution, and reproduction in any medium, provided you give appropriate credit to the original author(s) and the source, provide a link to the Creative Commons license, and indicate if changes were made. The Creative Commons Public Domain Dedication waiver (http://creativecommons.org/publicdomain/zero/1.0/) applies to the data made available in this article, unless otherwise stated. 
Besides the mode of selection, substitution rate is another essential factor which influences DNA sequence variation in plant organelles. Whereas the substitution rate is generally low in plant organellar genomes, it is highly elevated in some phylogenetic lineages, including the genus Silene [13]. Particularly two species - Silene noctiflora and Silene conica - achieved extreme rates of sequence and structural evolution in mitochondrial and plastid genomes $[14,15]$.

Silene vulgaris has an organellar genome substitution rate above the angiosperm average but is relatively slowly evolving compared to other Silene species $[16,17]$. However, intraspecific structural rearrangements in the mitochondrial genome of $S$. vulgaris are extreme, involving not only frequent losses and gains of intergenic DNA, but also changes in coding sequences $[16,18]$.

The accessibility of completely sequenced mitochondrial genomes of $S$. vulgaris and progress in RNA-seq methods enable the construction of comprehensive mitochondrial transcriptomes in this species. Such comparisons of transcriptomes between $\mathrm{F}$ and $\mathrm{H}$ plants in $\mathrm{S}$. vulgaris have revealed candidate CMS genes in their mitochondrial genomes and found differences in RNA editing rates between the different haplotypes which increased intraspecific protein variation $[18,19]$.

The plastid genome of $S$. vulgaris has been studied to a lesser extent than the mitochondrial genome of this species. The complete sequence of the plastid genome of only a single haplotype has been published [15] and no comprehensive plastid transcriptome analysis of this species is available.

To gain more detailed insight into plastid genome evolution in $S$. vulgaris, we assembled complete plastid sequences from five haplotypes of this species, including two accessions from high mountains adapted to high altitudes and genetically distant from the remaining three haplotypes originating from lowland populations [20]. CMS is a complex phenotype, which is associated with profound changes in the expression of some mitochondrial and many nuclear genes [21-23]. However, plastid transcriptomes are rarely studied in connection with CMS and it is not known, whether the transcription of plastid genes is affected by the male-sterile phenotype in gynodioecious plants. We therefore compared plastid transcriptomes of $\mathrm{F}$ and $\mathrm{H}$ plants in two of the haplotypes of S. vulgaris (KRA and KOV), for which mitochondrial transcriptomes are also available $[18,19]$. The CMS candidate genes were identified in both haplotypes, which would make possible to relate a potential impact of CMS on plastid transcriptome to specific CMS candidates. We did not detect any significant distinctions between the sexes but found interesting differences between transcriptomes of the two $S$. vulgaris haplotypes.

\section{Results}

\section{Complete plastid genomes of S. vulgaris}

We assembled five complete plastid genomes of $S$. vulgaris from Eurasia - the haplotypes D11, VS1, ZE2, KRA and KOV (Table 1). They ranged in length from 151,463 bp to 151,572 bp and contained a long single copy region (LSC), a short single copy region (SSC), and two inverted repeats (IRs) (Table 2). The boundaries between repeat and single copy regions and gene content were identical to the previously published plastid genome of S. vulgaris SD2 [15].

We identified the positions of simple sequence repeats (SSR), short arrays of tandem repeat units, in the six plastid genomes of $S$. vulgaris under study. We found 871 mononucleotide repeats longer than five nucleotides, but only 46 of them were longer than nine nucleotides (Additional file 1: Data Set 1). In addition, there were 62 dinucleotides, eight trinucleotides, eight tetranucleotides, and only one pentanucleotide. SSRs represent useful markers in population genetic studies owing to their variability. Within-individual variations in the number of mononucleotide units, arisen due to heteroplasmy, was observed in most mononucleotide regions. SSRs with a repeat unit higher than two nucleotides, not affected by heteroplasmy, can therefore be recommended for plastid genotyping in S. vulgaris. We found

Table 1 Collection sites of Silene vulgaris accessions analyzed in this study

\begin{tabular}{|c|c|c|c|c|c|}
\hline Haplotype & Region & Location & Latitude & Longitude Altitude (m a. s. I) & Reference \\
\hline D11 & Europe & $\begin{array}{l}\text { Austria, the Alps } \\
\text { Dachstein }\end{array}$ & 47.456802 & 13.6219861790 & This study \\
\hline VS1 & Europe & $\begin{array}{l}\text { Czech Republic } \\
\text { Jeseníky Mts. } \\
\text { Vřesová studánka } \\
\text { (Heidebrünnel) }\end{array}$ & 50.145429 & 17.1341761295 & This study \\
\hline ZE2 & Europe & $\begin{array}{l}\text { Netherlands, } \\
\text { Zandvoort }\end{array}$ & 52.374868 & 4.5340941 & This study \\
\hline KOV & Europe & $\begin{array}{l}\text { Czech Republic } \\
\text { Kováry near Prague }\end{array}$ & 50.185833 & 14.253783270 & {$[16]$} \\
\hline KRA & Asia & $\begin{array}{l}\text { Russia } \\
\text { Krasnoyarsk, Siberia }\end{array}$ & Not known & Not known about 290 & {$[18]$} \\
\hline
\end{tabular}


Table 2 Summary of six plastid genomes of S. vulgaris compared to the plastid genome of S. latifolia. The numbers of indels and nucleotide substitutions in the complete plastid genome alignments of the respective accessions with S. vulgaris SD2 are given

\begin{tabular}{llllllll}
\hline Plastid Genome & Accession Number & Size $(\mathrm{bp})$ & LSC (bp) & SSC (bp) & IR (Bp) & Indels & Substitutions \\
\hline SD2 & JF715057 & 151,583 & 82,258 & 17,309 & 26,008 & - & - \\
KOV & MH890612 & 151,463 & 82,180 & 17,303 & 25,990 & 35 & 80 \\
ZE2 & MK473866 & 151,572 & 82,257 & 17,339 & 25,986 & 33 & 35 \\
KRA & MH890613 & 151,486 & 82,215 & 17,307 & 25,982 & 87 & 114 \\
D11 & MK473868 & 151,484 & 82,208 & 17,350 & 25,963 & 92 & 97 \\
VS1 & MK473867 & 151,511 & 82,256 & 17,316 & 25,969 & 112 & 212 \\
S. latifolia & JF715055 & 151,736 & 82,704 & 17,220 & 25,906 & 397 & 1880 \\
\hline
\end{tabular}

19 positions of di-, tri-, or tetranucleotides, which varied among the analyzed plastid genomes of S. vulgaris.

\section{Phylogenetic relationships and sequence polymorphism} Plastid haplotypes VS1 and D11 of the high mountain $S$. vulgaris populations, occurring at the altitudes above $1200 \mathrm{~m}$ a. s. l, diverged first on the phylogenetic tree constructed on the basis of concatenated protein-coding sequences and with S. latifolia as an outgroup (Fig. 1b). The same topology was confirmed when entire plastid sequences except for homopolymers larger than five were used (Fig. 1a). In the latter phylogenetic tree, the position of the KRA haplotype from Siberia and D11 haplotype from the Alps was not resolved. The results a

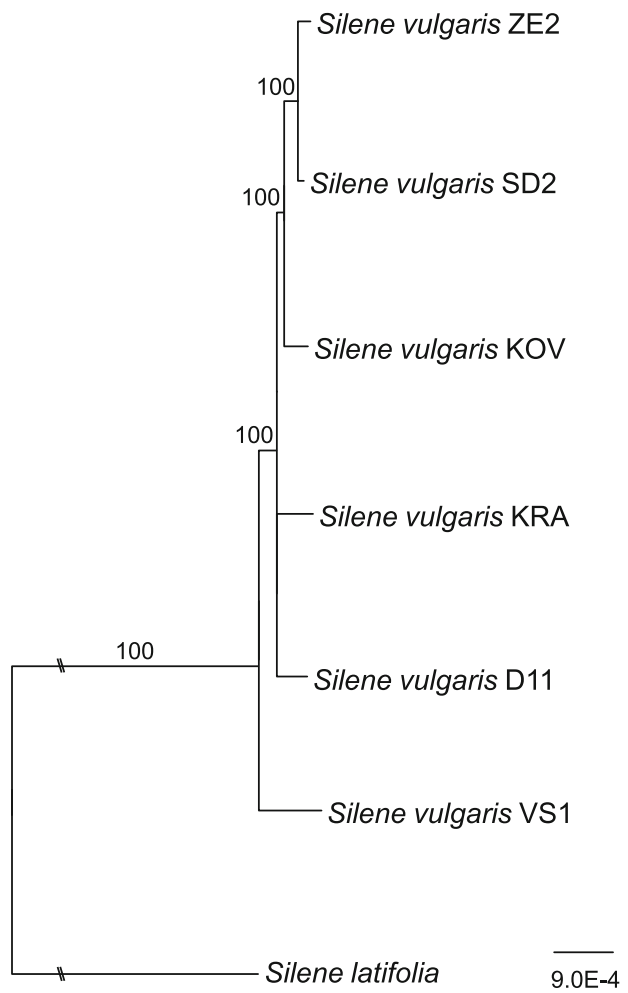

b

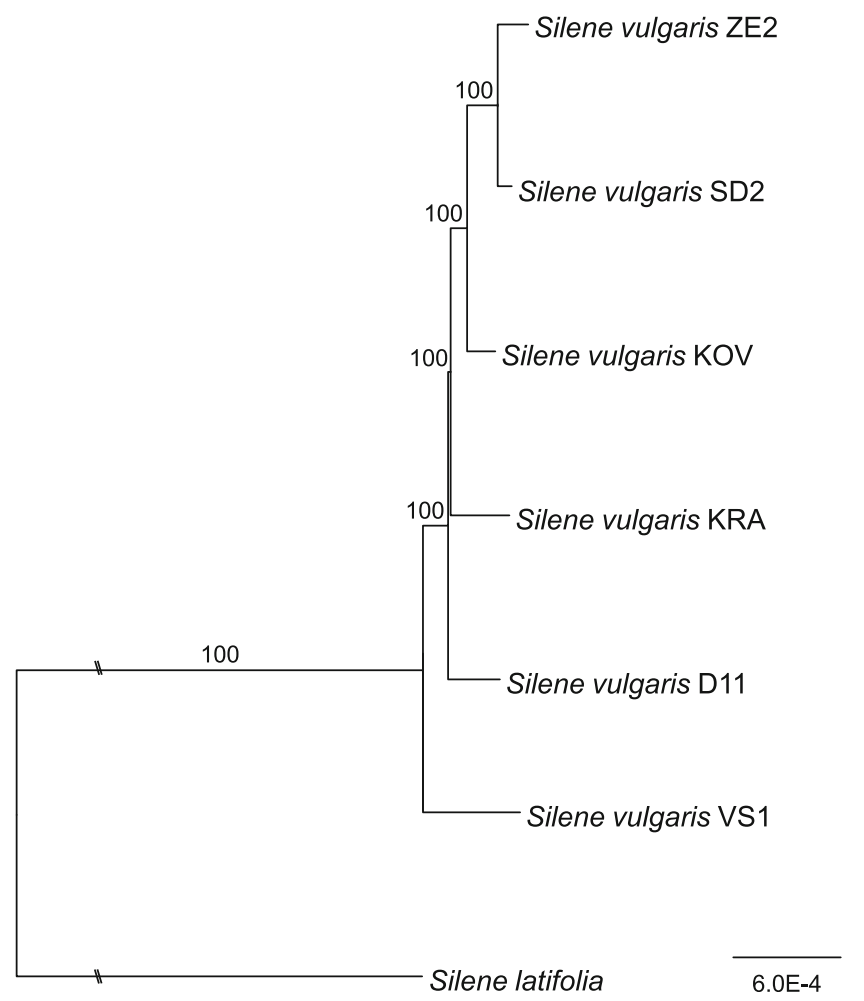

Fig. 1 Maximum likelihood phylogenetic trees for various plastid haplotypes of Silene vulgaris. a based on all sites of the plastid genome except for homopolymer sites larger than five nucleotides; b plastid coding regions only. Silene latifolia was used as outgroup. Long branches were shortened by 50\%, marked by two diagonal slashes. The scale bar indicates the number of substitutions per site. Branches with bootstrap support below 60\% were collapsed to polytomies. Phylogenetic trees were computed through the CIPRES webportal with RAxML v. 8.2.10 using 1000 bootstraps and the GTRGAMMA model 
obtained by maximum-likelihood (ML) method were consistent with the outputs generated by MrBayes, except that the position of KRA and D11 was always resolved (Additional file 2: Figure S1, Additional file 3: Figure S2).

The number of indels in pairwise alignments of individual plastid genomes of $S$. vulgaris varied from 33 to 112, and nucleotide substitutions ranged from 35 to 212 (Table 2). The highest number of the polymorphisms was found in the alignments with the haplotype VS1 from the Jeseníky Mts, consistent with its divergence's basal position within phylogenetic tree of $S$. vulgaris haplotypes. The indels occurred in 63 intergenic regions, in 10 introns, and in two coding regions ( $n d h D$ and $y c f 1$ ), which also showed an elevated number of nonsynonymous substitutions (Additional file 1: Data Set 3).

S. vulgaris plastid genes varied in their degree of polymorphism. Thirty of 77 unique protein coding genes were identical, and additional 25 genes carried only synonymous segregating sites and therefore encoded proteins identical among the six plastid haplotypes. Only 22 genes, including $a c c D$, matK, rpoB or $y c f 2$, carried at least one non-synonymous segregating site (Fig. 2). The substitution in the rpl20 gene in the haplotypes SD2 and ZE2 created a premature stop codon which shortened the rpl20 protein by the last three amino acids.

Two highly polymorphic genes - ycf1 and $n d h F-$ contained the vast majority of polymorphisms: 48 of the total 69 non-synonymous segregating sites. (Additional file 1. Data Set 2). A detailed inspection of $\mathrm{Ka} / \mathrm{Ks}$ for these two genes revealed values $>1.0$, which indicate relaxed or positive selection. This was the case in all the pairwise comparisons among the $S$. vulgaris haplotypes for $y c f 1$. However, only the $n d h F$ alignments which comprised the mountain haplotypes VS1 and D11 exhibited high Ka/Ks (Additional file 1: Data Set 4).

\section{Plastid transcriptomes of S. vulgaris KRA and KOV}

We generated plastid transcriptomes of two haplotypes of $S$. vulgaris KRA and KOV $[18,19]$ using the data sets previously employed to construct the mitochondrial transcriptomes. We compared gene coverages and RNA editing rates in flower buds between $\mathrm{F}$ and $\mathrm{H}$ individuals and between the two haplotypes.

We compared depth of coverage of protein coding genes, because rRNA was removed before cDNA library preparation and small RNAs ( $<100 \mathrm{nt}$ ) including tRNAs were lost in the course of RNA extraction. Depth of coverage was similar in $\mathrm{F}$ and $\mathrm{H}$ plants in both haplotype $\mathrm{KOV}$ and KRA, no gene was significantly differentially expressed between the sexes. The depth of coverage could not be directly compared between the KOV and KRA plastid genomes, because Illumina sequencing was performed on different platforms and produced reads of different lengths for each plastid transcriptome. We therefore compared the sets of highly and lowly covered genes between the two haplotypes. The genes $p s b A, r b c L, p s b E$, rps14 and rps16 were among the most highly expressed, whereas the $p s b N$ was among the least expressed genes both in KRA and KOV plants (Additional file 1: Data Set 5), which indicates general similarity between the two plastid transcriptomes. The $n d h F$ gene showed a lower transcript level than other genes encoding the NADH complex proteins as documented by the heat map in Additional file 4: Figure S3.

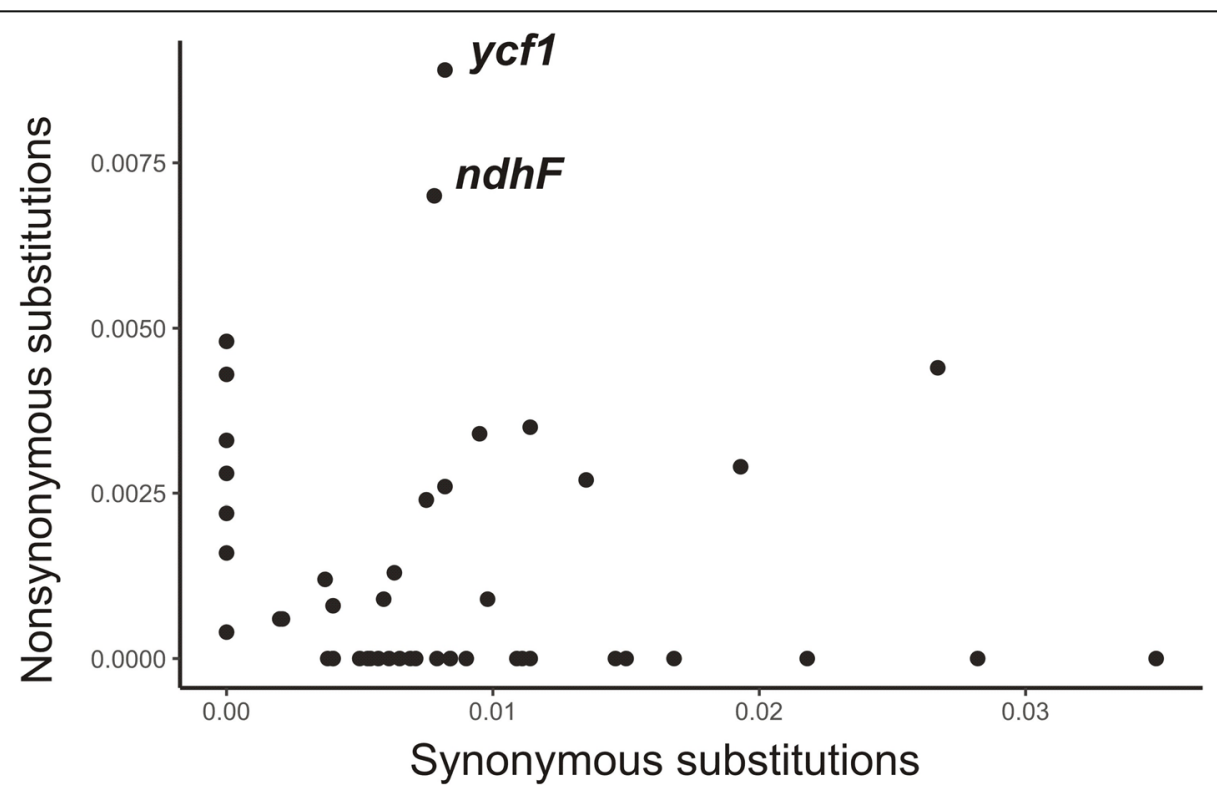

Fig. 2 Variation in synonymous and nonsynonymous single nucleotide polymorphisms among S. vulgaris plastid protein genes. The number of segregating sites per synonymous or nonsynonymous site was calculated by DnaSp 


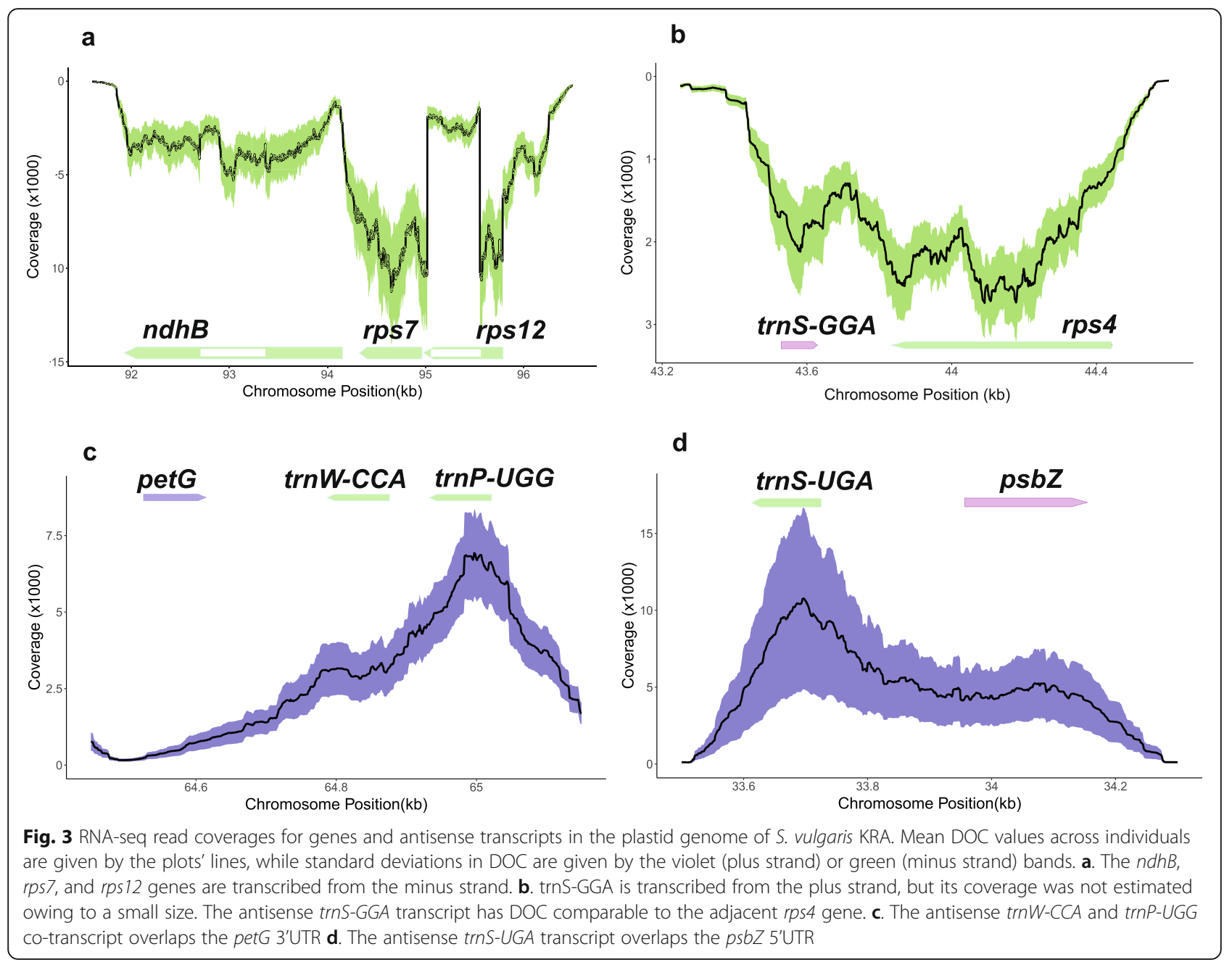

Introns were covered to a lower extent than adjacent exons in most plastid genes, but their coverage reached levels comparable to exons in some genes, for example in $n d h B$ (Fig. 3a).

\section{Antisense non-coding transcripts in plastid transcriptomes of $S$. vulgaris KRA and KOV}

We identified five antisense non-coding transcripts > $100 \mathrm{nt}$ with transcript abundance comparable to protein coding genes, overlapping trn genes (Additional file 1: Data Set 6), three of them were found in both KRA and $\mathrm{KOV}$ transcriptomes, two were revealed in KOV only. The trnS-GGA and trnW-CCA - trnP-UGG antisense transcripts corresponded to the 3'UTRs of the rps4 gene and pet $G$ genes, respectively. The trnS-UGA antisense transcript colocalized with the 5'UTR of the $p s b Z$ gene (Fig. 3b, c, d).

The antisense transcript spanning the $5^{\prime} \mathrm{UTR}$ and the start of the rps14 gene (Fig. 4a), was the most abundant atisense transcript derived from protein coding genes in
$\mathrm{KOV}$, but it was absent in the KRA transcriptome. Another antisense transcript derived from the rps19 and rpl 2 genes was revealed in both $S$. vulgaris transcriptomes under study (Fig. 4b). The $p s b N$ gene coding for a small transmembrane protein necessary for the assembly of photosystem II [24] was transcribed from minus DNA strand in sense orientation and from the opposite strand in antisense orientation as a part of the longer psbT$p s b H$ transcript. The antisense $p s b N$ transcript exhibited much higher depth of coverage than the sense $p s b N$ transcript coding for the psbN protein (Fig. 4c).

Similarly with protein-coding genes, no statistically significant differences in antisense transcript levels were found between $\mathrm{F}$ and $\mathrm{H}$ plants. In contrast, the abundance of antisense transcripts differed between the KOV and KRA transcriptomes of $S$. vulgaris more than the transcript levels of protein coding genes. The most remarkable distinction was found in the antisense rps14 transcript (Fig. 4a), which was highly covered in KOV, but completely missing in KRA. 

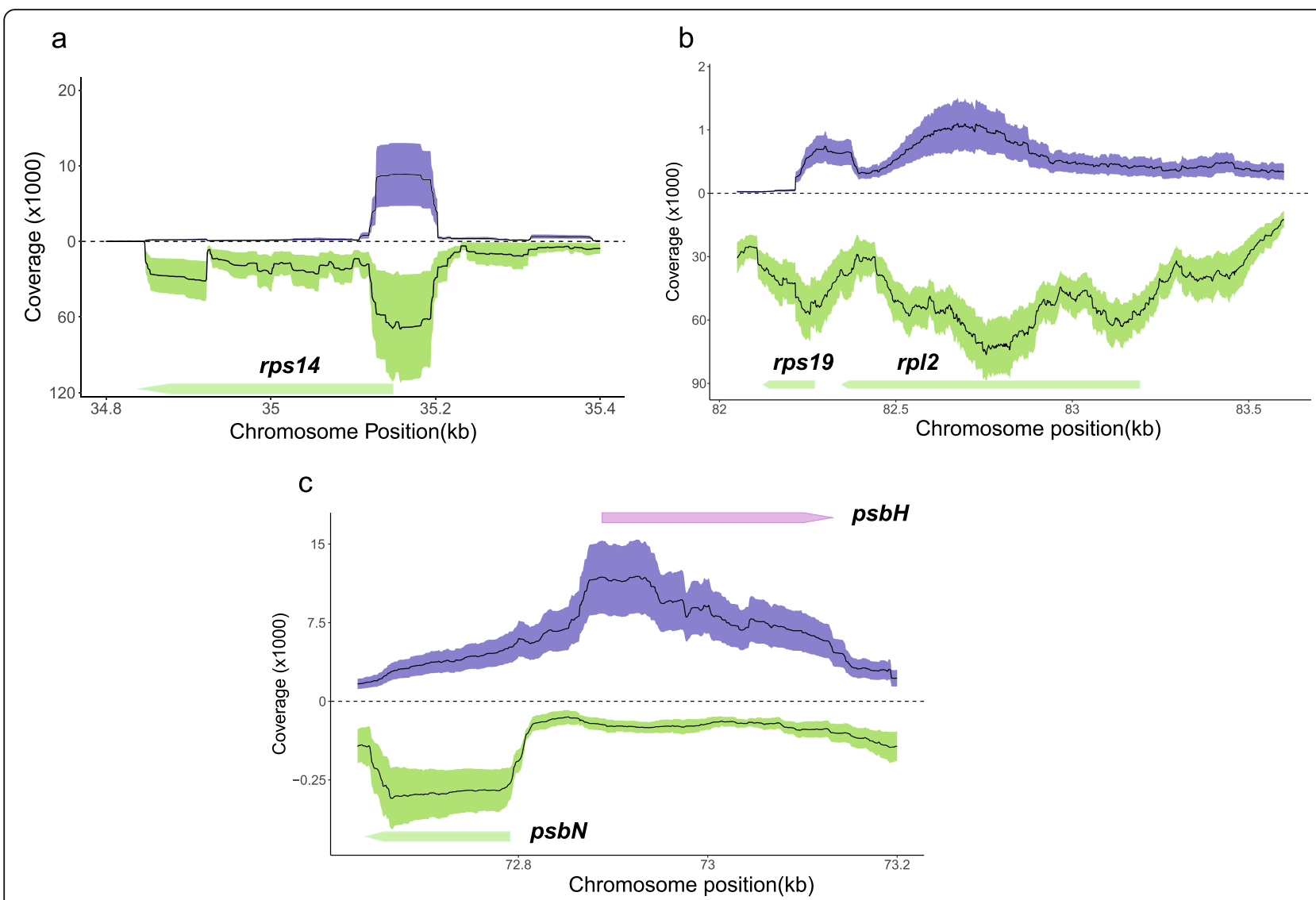

Fig. 4 RNA-seq read coverages for genes and antisense transcripts in the plastid genome of S. vulgaris. Mean DOC values across individuals are given by the plots' lines, while standard deviations in DOC are given by the violet (plus strand) or green (minus strand) bands. $\mathbf{a}$. The antisense RNA spans the $5^{\prime} U T R$ and $5^{\prime}$ end of the rps 14 gene, which is transcribed from the minus strand. $\mathbf{b}$. The antisense transcripts of rps 19 and $r p / 2$ in $S$. vulgaris KRA c. The $p s b N$ gene is transcribed in sense orientation less than in antisense orientation

The depth of coverage in the KRA and KOV plastid transcriptome estimated by the ChloroSeq pipeline [25] was in agreement with the results stated above, which were obtained using GSNAP according to [19] (Additional file 1: Data Set 5).

\section{RNA editing positions in plastid genomes of $S$. vulgaris KRA and KOV}

We identified 51 unique $\mathrm{C}$ to $\mathrm{U}$ editing sites in the plastid genomes of $S$. vulgaris KRA and KOV, 38 of them located in protein coding regions, two of them in introns, and 11 in intergenic regions. Editing sites in rRNAs and tRNAs were not evaluated due to their biased coverage caused by the sample preparation methods. Most edits (95\%) in coding sequences were non-synonymous, changing the amino acid composition; only two editing sites were silent. The most frequently edited genes were $n d h B$ (9 edits), $n d h D$ (4 sites), and $n d h A$ (4 sites).

We compared S. vulgaris editing sites with eight angiosperm species, for which plastid editome had comprehensively been studied: Amborella trichopoda, Cucumis sativus [26], Spirodela polyrhiza [27], Aegilops tauschii
[28], Arabidopsis thaliana [29], Hevea brasiliensis [30], Nicotiana tabacum [31], Vigna radiata [32] (Table 3). The majority of the 38 edits in protein coding regions identified in S. vulgaris were either edited, or $\mathrm{C}$ was replaced with $\mathrm{T}$ at the DNA level in most angiosperms under comparison. The two silent edits were not conserved across angiosperms. A highly edited position in the rps16 intron was also edited in A. tauschii and replaced with T in DNA of A. trichopoda and A. thaliana, which may indicate its functional importance. The intergenic regions could not have been reliably aligned across the angiosperm species under comparison.

\section{The rate of RNA editing in plastid transcriptomes of $S$. vulgaris KRA and KOV}

The editing rate higher than $80 \%$ in at least one of the two S. vulgaris transcriptomes was determined in 26 of 38 edits in protein coding genes, all of them were nonsynonymous (Additional file 1: Data Set 7). Both silent sites were edited only about $50 \%$ or less. An editing event introduced a premature stop codon in about $10 \%$ of the $n d h J$ transcripts, but this position was not edited in other 
angiosperms under comparison. Editing is necessary to create a start codon in the $n d h D$ gene in all angiosperms, where $\mathrm{C}$ is present in the second position of the coding region. However, all KRA and KOV plants were edited < $15 \%$ in this position, which means that only a small portion of the $n d h D$ transcripts encoded a functional protein.

In contrast with protein coding genes, only two of 11 editing positions in intergenic regions were edited more than $80 \%$. One of them was located in 3'UTR of the atpH gene, the second one in the position 64,933 of the KRA plastid genome in the trnW-CCA - trnP-UGG antisense transcript.

Editing rates in the KRA and KOV plastid transcriptomes were mutually congruent, exhibiting moderate diffrences in the positions with intermediate rates 40 $70 \%$ (Fig. 5). The most remarkable difference was found in the position 50 of the $p s b Z$ coding region, which changed leucine for serine. No editing was observed in this position in the KRA haplotype, whereas approximately $6 \%$ of $p s b Z$ transcripts, which represented about four hundred reads, were edited in each of six KOV plants (Table 3). Editing of this position varied across angiosperms. The same position was edited in A. thaliana and S. polyrhiza, while no editing was reported in $A$. tauschii, $H$. brasiliensis, or $C$. sativus. T replaced $C$ in this position in the plastid genomes of $N$. tabacum and $V$. radiata. To verify editing of this position in Caryophyllales, we downloaded the transcriptomic data of four Silene species, Agrostemma githago and Spinacia oleracea from the SRA archive and mapped them against the $p s b Z$ sequence. We found high editing of the position 50 of $p s b Z$ in $S$. conica and no editing in spinach, S. noctiflora and Silene paradoxa. This position was edited to a lower extent in Silene latifolia and A. githago (Additional file 1: Data Set 8). Although the coverage of psbZ was low in most data sets, it showed variable editing across close relatives of $S$. vulgaris, the pattern similar to scattered editing at high taxonomic level.

No statistically significant differences of editing rates between $\mathrm{F}$ and $\mathrm{H}$ individuals were observed between the KOV or KRA haplotypes. The estimates of editing rates provided by the GSNAP [19] and the ChloroSeq pipeline [25] were consistent (Additional file 5: Figure S4).

\section{Discussion}

\section{Variation in six plastid genomes of S. vulgaris}

This comparison of six completely sequenced plastid genomes of $S$. vulgaris revealed identical structures and moderate sequence differences, which is in line with the previously reported slow plastid evolutionary rate of this Silene species, unlike fast evolving S. noctiflora and S. conica [15], or Silene paradoxa and Lychnis chalcedonica [17]. The S. vulgaris plastid genome is more similar to the plastid genome of S. latifolia in terms of structure and evolutionary rate. Our study involved two accessions from mountain populations and one accession collected in sandy beach close to the sea. The mountain haplotypes diverged first in the phylogenetic tree, confirming their genetic distance from lowland populations. In contrast, the beach accession ZE2 clustered together with

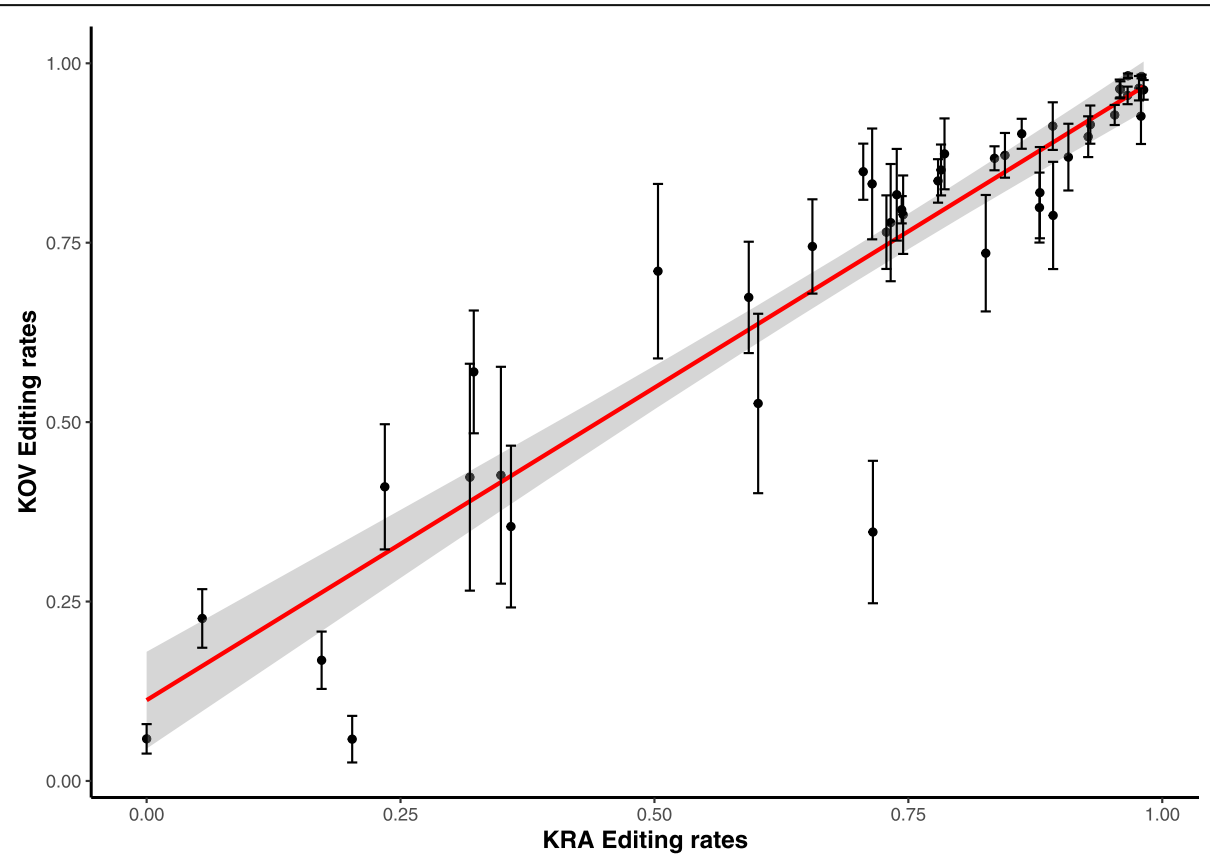

Fig. 5 RNA editing extent in S. vulgaris plastids. The haplotypes KOV and KRA are compared. Mean values ( \pm SD) calculated from six individuals are plotted, a 95\% confidence band for the observed data is given in gray within plot 
the remaining populations, suggesting it recently diverged likely becoming isolated in the process of adaptation to the ecologically divergent seashore habitat with an increased salinity.

High variation in plastid evolutionary rates exist not only among the Silene species, but also among individual plastid genes [17]. We found prominent distinctions in substitution rate among the plastid genes also at the within-species level in S. vulgaris. Mainly two genes, $y c f 1$ and $n d h F$, accumulated a high number of nonsynonymous substitutions. Whereas the $y c f 1$ gene exhibited high acceleration in substitution rate across all Silene species and also other angiosperms, the $n d h F$ gene belonged among the more slowly evolving genes [17]. Our study found elevated $\mathrm{Ka} / \mathrm{Ks}$ in the $n d h F$ pairwise alignments which included at least one mountain haplotype of $S$. vulgaris. The $\mathrm{Ka} / \mathrm{Ks}$ values close to 1 indicate relaxed selection, the values $>1$ may imply positive selection. Our results suggest distinct selection acting on the $n d h F$ gene in mountain populations compared to lowland plants of S. vulgaris. The habitats above timberline are exposed to intense light including UV. The increased content of flavonoids in the mountain populations of $S$. vulgaris has been interpreted as a defense against excessive light [33]. It is possible that the non-synonymous substitutions in the $n d h F$ may be also related to adaptation to a higher light intensity in high altitudes.

\section{RNA editing in plastid transcriptomes of $S$. vulgaris}

We found no significant difference in the plastid transcriptomes of flower buds in terms of coverage and RNA editing rate between $\mathrm{F}$ and $\mathrm{H}$ plants neither in the KRA nor KOV haplotype of $S$. vulgaris. This indicates that plastid transcriptomes were not affected by the processes underlying pollen abortion in two haplotypes with distinct CMS types $[18,19]$. However, as we analyzed total RNA from entire flower buds, it cannot be excluded that the transcription in plastids of some specific tissues, e.g., tapetum is still influenced by CMS.

Thirty-eight RNA editing sites were revealed in the protein coding genes in the $S$. vulgaris transcriptomes. This value is comparable to those reported in other eudicots: 34 edits in A. thaliana [29], 40 edits in $V$. radiata [32], or 51 edits in C. sativus [26]. This number is much lower than 138 editing sites discovered in the plastid protein coding genes of the basal angiosperm $A$. trichopoda, which is in agreement with a general trend of gradual loss of plastid edits in the course of the evolution of flowering plants [26]. The loss of editing by the replacement of $\mathrm{C}$ for $\mathrm{T}$ in genomic DNA occurred in parallel to a similar extent, but it affected distinct sites in various lineages (Table 3 ).

The vast majority of editing sites in protein coding genes (36) were non-synonymous, changing the encoded amino acid. With a single exception (low-rate edits introducing a premature stop codon in $n d h J)$, all nonsynonymous sites were conserved - they were either edited or $\mathrm{C}$ was replaced with $\mathrm{T}$ in at least one species under comparison.

Most, but not all non-synonymous sites were edited more than $80 \%$. An interesting example of a largely unedited essential position was observed in the $n d h D$ gene, where editing established the start codon in only about $15 \%$ of transcripts, which strongly reduced the abundance of correct mRNA and might have decreased the production of functional NdhD protein. The same position was low-edited in non-photosynthetic organs (roots, etiolated seedlings) of A. thaliana [34]. As our transcriptomes were derived from young flower buds, which contained both photosynthetic and nonphotosynthetic tissues, low editing of the $n d h D$ start codon might have reflected a lack of editing in some floral tissues. Owing to its possible strong impact on the $\mathrm{NdhD}$ protein abundance and the function of $\mathrm{NDH}$ complex, editing of the start codon of might have been employed to regulate the expression of the $n d h D$ gene. Although the primary function of organellar RNA editing in plants resides in the restoration of conserved amino acids [35], its role in posttranscriptional gene expression control shall be considered [36]. Additional examples of developmental stage- and tissue-specific RNA editing were previously described in plastids of tomato [37] or potato [38].

The two haplotypes of $S$. vulgaris differed in editing extent of the $p s b Z$ gene. One haplotype was edited to a low extent, but consistently across all six individuals of both sexes, the other one was not edited at all. Editing rate of the position 50 of $p s b Z$ varied across angiosperms under comparison, where all the possibilities, namely editing, replacement of $\mathrm{C}$ for $\mathrm{T}$, and zero editing, were observed (Table 4). No comprehensive plastid transcriptome of Silene has been published, but mining available transcriptomic data from GenBank showed similar pattern of the variation in $p s b Z$ editing rate across close relatives of $S$. vulgaris as across angiosperms. The psbZ protein is an important component the supramolecular architecture of photosystem II $[39,40]$, whose subunits belong among the least divergent genes in Silene [17], most likely owing to the action of purifying selection. The variation in $p s b Z$ RNA editing across angiosperms, Caryophyllaceae, and even within a single species $S$. vulgaris is therefore surprising. The editing of the position 50 replaces $S$ for $L$ in the middle of the first transmembrane domain of psbZ [40]. It is possible that this exchange does not have noticeable impact on the protein function. The variation in RNA editing among Arabidopsis species, affecting functionally less important sites, was recently described [41], but the position 50 of $p s b Z$ was uniformly edited in the Arabidopsis species 
Table 3 The comparison of editing between the plastid genomes of S. vulgaris KRA and S. vulgaris KOV and eight angiosperm species. Ambo. - Amborella trichopoda, Spiro. - Spirodela polyrhiza, Aegilops tauschii, Arab. - Arabidopsis thaliana, Hevea brasiliensis, Nicot. - Nicotiana tabacum, Vigna radiata, Cucumis sativus

\begin{tabular}{|c|c|c|c|c|c|c|c|c|c|c|c|c|c|}
\hline \multirow[b]{2}{*}{ Gene position } & \multirow[b]{2}{*}{ Effect/Notes } & $\begin{array}{l}\text { Genome } \\
\text { position }\end{array}$ & Edit rate & $\begin{array}{l}\text { Genome } \\
\text { position }\end{array}$ & Edit rate & Ambo. & Spiro. & Aegilops & Arab. & Hevea & Nicot. & Vigna & Cucumis \\
\hline & & \multicolumn{2}{|l|}{ KRA } & \multicolumn{10}{|l|}{ KOV } \\
\hline & rps 16 intron & 5004 & $69 \%$ & 4996 & $30 \%$ & NA & $\mathrm{NA}$ & NA & $\mathrm{NA}$ & C & $\mathrm{NA}$ & $\mathrm{NA}$ & $\mathrm{NA}$ \\
\hline & rps 16 intron & 5325 & $93 \%$ & 5317 & $93 \%$ & $\mathrm{~T}$ & C & Edit & $\mathrm{T}$ & C & C? & C? & $C ?$ \\
\hline \multirow[t]{3}{*}{ atpAeU914SL } & $\mathrm{TCA}(\mathrm{S})=>\pi \mathrm{TA}(\mathrm{L})$ & 10,003 & $96 \%$ & 10,000 & $96 \%$ & Edit & $\mathrm{T}$ & $\mathrm{T}$ & $\mathrm{T}$ & $\mathrm{T}$ & $\mathrm{T}$ & $\mathrm{T}$ & $\mathrm{T}$ \\
\hline & intergenic & 12,532 & $92 \%$ & 12,531 & $93 \%$ & NA & NA & NA & NA & NA & NA & NA & NA \\
\hline & intergenic & 13,336 & $50 \%$ & 13,336 & $72 \%$ & NA & NA & NA & NA & NA & NA & NA & NA \\
\hline rps2eU248SL & $\mathrm{TCA}(\mathrm{S})=>\pi \mathrm{TA}(\mathrm{L})$ & 14,920 & $98 \%$ & 14,920 & $97 \%$ & C & $\mathrm{T}$ & $\mathrm{T}$ & $\mathrm{T}$ & Edit & C & Edit & Edit \\
\hline rpoC2eU2968HY & $\operatorname{CAT}(H)=>\operatorname{TAT}(Y)$ & 16,608 & $70 \%$ & 16,586 & $85 \%$ & C & $\mathrm{T}$ & C & $\mathrm{T}$ & C & C & C & C \\
\hline rpoBeU566SL & $\mathrm{TCG}(\mathrm{S})=>\operatorname{TTG}(\mathrm{L})$ & 25,178 & $52 \%$ & 25,156 & $80 \%$ & C & $\mathrm{T}$ & Edit & $\mathrm{T}$ & $\mathrm{T}$ & $\mathrm{T}$ & Edit & Edit \\
\hline rpoBeU551SL & $\mathrm{TCA}(\mathrm{S})=>\operatorname{TT} \mathrm{A}(\mathrm{L})$ & 25,193 & $49 \%$ & 25,171 & $76 \%$ & Edit & $\mathrm{T}$ & Edit & Edit & Edit & Edit & Edit & Edit \\
\hline rpoBeU473SL & $\mathrm{TCA}(\mathrm{S})=>\mathrm{TT} \mathrm{A}(\mathrm{L})$ & 25,271 & $78 \%$ & 25,249 & $83 \%$ & Edit & Edit & Edit & $\mathrm{T}$ & $\mathrm{T}$ & Edit & $\mathrm{T}$ & $\mathrm{T}$ \\
\hline psbZeU50SL & $\mathrm{TCA}(\mathrm{S})=>\operatorname{TT} \mathrm{A}(\mathrm{L})$ & 34,009 & 0 & 33,958 & $6 \%$ & C & Edit & C & Edit & C & $\mathrm{T}$ & $\mathrm{T}$ & C \\
\hline rps14eU80SL & $\mathrm{TCA}(\mathrm{S})=>\operatorname{TT} \mathrm{A}(\mathrm{L})$ & 35,133 & $98 \%$ & 35,071 & $96 \%$ & $\mathrm{~T}$ & $\mathrm{~T}$ & $\mathrm{~T}$ & Edit & Edit & Edit & Edit & $\mathrm{T}$ \\
\hline \multirow[t]{2}{*}{ ndhJeU160QX } & $\mathrm{CAA}(\mathrm{Q})=>\mathrm{TAA}($ Stop $)$ & 47,529 & $13 \%$ & 47,486 & $8 \%$ & C & C & C & C & C & C & C & C \\
\hline & intergenic & 47,740 & $32 \%$ & 47,697 & $45 \%$ & NA & NA & NA & NA & NA & NA & NA & NA \\
\hline \multirow[t]{2}{*}{ ndhKeU65SL } & $\mathrm{TCA}(\mathrm{S})=>\operatorname{TT} \mathrm{A}(\mathrm{L})$ & 48,408 & $65 \%$ & 48,365 & $77 \%$ & Edit & $\mathrm{T}$ & Edit & $\mathrm{T}$ & Edit & $\mathrm{T}$ & $\mathrm{T}$ & Edit \\
\hline & intergenic & 49,285 & $23 \%$ & 49,243 & $43 \%$ & NA & NA & NA & NA & NA & NA & NA & NA \\
\hline accDeU1337PL & $\mathrm{CCA}(\mathrm{P})=>\mathrm{CTA}(\mathrm{L})$ & 57,221 & $95 \%$ & 57,185 & $96 \%$ & Edit & $\mathrm{T}$ & $\mathrm{T}$ & $C)^{\mathrm{b}}$ & T & $\mathrm{T}$ & $\mathrm{T}$ & $\mathrm{T}$ \\
\hline psaleU85HY & $\operatorname{CAT}(H)=>\operatorname{TAT}(Y)$ & 57,642 & $71 \%$ & 57,601 & $82 \%$ & Edit & $\mathrm{T}$ & $\mathrm{T}$ & C & $\mathrm{T}$ & C & Edit & Edit \\
\hline psbleU2TM & $\mathrm{ACG}(\mathrm{T})=>$ ATG $($ Start $)$ & 62,667 & $96 \%$ & 62,630 & $98 \%$ & Edit & $\mathrm{T}$ & $\mathrm{T}$ & $\mathrm{T}$ & $\mathrm{T}$ & Edit & $\mathrm{T}$ & $\mathrm{T}$ \\
\hline \multirow[t]{2}{*}{ petLeU5PL } & $C C T(P)=>C T T(L)$ & 64,268 & $86 \%$ & 64,236 & $90 \%$ & Edit & $\mathrm{T}$ & $\mathrm{T}$ & Edit & Edit & $\mathrm{T}$ & Edit & $\mathrm{T}$ \\
\hline & intergenic & 64,933 & $83 \%$ & 64,902 & $86 \%$ & NA & NA & NA & NA & NA & NA & NA & NA \\
\hline clpPeU559HY & $\operatorname{CAT}(H)=>\operatorname{TAT}(Y)$ & 68,351 & $97 \%$ & 68,321 & $98 \%$ & Edit & $\mathrm{T}$ & $\mathrm{T}$ & Edit & Edit & $\mathrm{T}$ & Edit & Edit \\
\hline petBeU12W & Silent GTC $(\mathrm{V})=>\mathrm{GTT}(\mathrm{V})$ & 73,958 & $32 \%$ & 73,935 & $56 \%$ & A & C & A & $\mathrm{T}$ & C & A & $\mathrm{T}$ & G \\
\hline petBeU418RW & $\mathrm{CGG}(\mathrm{R})=>\mathrm{TGG}(\mathrm{W})$ & 74,364 & $97 \%$ & 74,341 & $93 \%$ & Edit & $\mathrm{T}$ & $\mathrm{T}$ & $\mathrm{T}$ & $\mathrm{T}$ & $\mathrm{T}$ & $\mathrm{T}$ & Edit \\
\hline rpoAeU200SF & $\mathrm{TCT}(\mathrm{S})=>\mathrm{TT}(\mathrm{F})$ & 77,018 & $93 \%$ & 76,983 & $89 \%$ & Edit & Edit & $\mathrm{T}$ & Edit & Edit & C & Edit & C \\
\hline ndhBeU1481PL & $\mathrm{CCA}(\mathrm{P})=>\mathrm{CTA}(\mathrm{L})$ & 91,996 & $89 \%$ & 91,961 & $80 \%$ & Edit & Edit & Edit & Edit & Edit & Edit & Edit & Edit \\
\hline ndhBeU836SL & $\mathrm{TCA}(\mathrm{S})=>\pi \mathrm{TA}(\mathrm{L})$ & 92,641 & $90 \%$ & 92,606 & $88 \%$ & $\mathrm{~T}$ & Edit & Edit & Edit & C & Edit & Edit & C \\
\hline ndhBeU830SL & $\mathrm{TCA}(\mathrm{S})=>\pi \mathrm{TA}(\mathrm{L})$ & 92,647 & $88 \%$ & 92,612 & $84 \%$ & Edit & Edit & Edit & Edit & Edit & Edit & Edit & Edit \\
\hline ndhBeU746SF & $\mathrm{TCT}(\mathrm{S})=>\mathrm{TT}(\mathrm{F})$ & 93,399 & $74 \%$ & 93,364 & $80 \%$ & $\mathrm{~T}$ & $\mathrm{~T}$ & $\mathrm{~T}$ & Edit & Edit & Edit & Edit & C \\
\hline ndhBeU737PL & $C C A(P)=>C T A(L)$ & 93,408 & $87 \%$ & 93,373 & $81 \%$ & Edit & Edit & Edit & $\mathrm{T}$ & $\mathrm{T}$ & Edit & Edit & Edit \\
\hline ndhBeU586HY & $\operatorname{CAT}(H)=>\operatorname{TAT}(Y)$ & 93,559 & $60 \%$ & 93,524 & $56 \%$ & Edit & Edit & Edit & Edit & Edit & Edit & Edit & Edit \\
\hline ndhBeU542TM & $\operatorname{ACG}(T)=>\operatorname{ATG}(M)$ & 93,603 & $30 \%$ & 93,568 & $45 \%$ & Edit & Edit & $\mathrm{T}$ & $\mathrm{T}$ & Edit & $\mathrm{T}$ & Edit & Edit \\
\hline ndhBeU467PL & $C C A(P)=>C T A(L)$ & 93,678 & $73 \%$ & 93,643 & $79 \%$ & Edit & Edit & Edit & Edit & Edit & Edit & $\mathrm{T}$ & Edit \\
\hline ndhBeU149SL & $\mathrm{TCA}(\mathrm{S})=>\operatorname{TT} \mathrm{A}(\mathrm{L})$ & 93,996 & $58 \%$ & 93,961 & $69 \%$ & Edit & Edit & Edit & Edit & Edit & Edit & Edit & Edit \\
\hline ndhDeU1298SL & $\mathrm{TCA}(\mathrm{S})=>\pi \mathrm{TA}(\mathrm{L})$ & 113,839 & $96 \%$ & 113,810 & $96 \%$ & $\mathrm{~T}$ & $\mathrm{~T}$ & $\mathrm{~T}$ & $\mathrm{~T}$ & $\mathrm{~T}$ & C & $\mathrm{T}$ & $\mathrm{T}$ \\
\hline ndhDeU887PL & $\mathrm{CCC}(\mathrm{P})=>\mathrm{CTC}(\mathrm{L})$ & 114,250 & $84 \%$ & 114,221 & $87 \%$ & $\mathrm{~T}$ & $\mathrm{~T}$ & $\mathrm{~T}$ & Edit & Edit & $\mathrm{T}$ & $\mathrm{T}$ & Edit \\
\hline ndhDeU383HY & $\operatorname{CAT}(H)=>\operatorname{TAT}(Y)$ & 114,754 & $78 \%$ & 114,722 & $87 \%$ & Edit & $\mathrm{T}$ & $\mathrm{T}$ & Edit & $\mathrm{T}$ & Edit & Edit & Edit \\
\hline ndhDeU2TM & $\mathrm{ACG}(\mathrm{T})=>$ ATG $($ Start $)$ & 115,135 & $13 \%$ & 115,103 & $16 \%$ & Edit & Edit & $\mathrm{T}$ & Edit & $\mathrm{T}$ & Edit & Edit & Edit \\
\hline ndhGeU50TI & $\mathrm{ACA}(\mathrm{T})=>\mathrm{ATA}(\mathrm{I})$ & 116,860 & $78 \%$ & 116,828 & $86 \%$ & C & $\mathrm{T}$ & $\mathrm{T}$ & Edit & $\mathrm{T}$ & $C)^{c}$ & $C)^{d}$ & Edit \\
\hline ndhAeU1073SF & $\mathrm{TCC}(\mathrm{S})=>\mathrm{TTC}(\mathrm{F})$ & 117,937 & $83 \%$ & 117,905 & $75 \%$ & Edit & Edit & Edit & $\mathrm{T}$ & $\mathrm{T}$ & Edit & Edit & $\mathrm{T}$ \\
\hline ndhAeU961PS & $\mathrm{CCT}(\mathrm{P})=>\mathrm{TCT}(\mathrm{S})$ & 118,049 & $74 \%$ & 118,017 & $83 \%$ & Edit & Edit & $\mathrm{T}$ & $\mathrm{T}$ & Edit & Edit & $\mathrm{T}$ & $\mathrm{T}$ \\
\hline
\end{tabular}


Table 3 The comparison of editing between the plastid genomes of S. vulgaris KRA and S. vulgaris KOV and eight angiosperm species. Ambo. - Amborella trichopoda, Spiro. - Spirodela polyrhiza, Aegilops tauschii, Arab. - Arabidopsis thaliana, Hevea brasiliensis, Nicot. - Nicotiana tabacum, Vigna radiata, Cucumis sativus (Continued)

\begin{tabular}{|c|c|c|c|c|c|c|c|c|c|c|c|c|c|}
\hline & & $\begin{array}{l}\text { Genome } \\
\text { position }\end{array}$ & Edit rate & $\begin{array}{l}\text { Genome } \\
\text { position }\end{array}$ & Edit rate & Ambo. & Spiro. & Aegilops & Arab. & Hevea & Nicot. & Vigna & Cucumis \\
\hline Gene position & Effect/Notes & KRA & & KOV & & & & & & & & & \\
\hline$\overline{\text { ndhAeU566SL }}$ & $\mathrm{TCA}(\mathrm{S})=>\mathrm{TT} \mathrm{A}(\mathrm{L})$ & 118,444 & $6 \%$ & 118,412 & $21 \%$ & Edit & Edit & Edit & $\mathrm{T}$ & Edit & $T$ & $T$ & Edit \\
\hline ndhAeU341SL & $\mathrm{TCA}(\mathrm{S})=>\mathrm{TT} \mathrm{A}(\mathrm{L})$ & 119,692 & $89 \%$ & 119,660 & $73 \%$ & $\mathrm{~T}$ & $\mathrm{~T}$ & $\mathrm{~T}$ & Edit & C & Edit & Edit & Edit \\
\hline \multirow[t]{2}{*}{ ndhHeU303II } & Silent ATC $(I)=>$ ATT $(I)$ & 120,913 & $29 \%$ & 120,881 & $7 \%$ & C & C & $\mathrm{T}$ & C & C & C & C & C \\
\hline & Editing below threshold) ${ }^{a}$ & & & & & & & & & & & & \\
\hline \multirow[t]{7}{*}{ psaleU82LF } & $\mathrm{CTT}(\mathrm{L})=>\Pi \Pi(\mathrm{F})$ & 57,639 & $5 \%$ & 57,598 & $4 \%$ & C & C & C & C & C & C & C & C \\
\hline & intergenic & 57,712 & $9 \%$ & 57,671 & $15 \%$ & NA & NA & NA & NA & NA & NA & NA & NA \\
\hline & intergenic & 57,717 & $7 \%$ & 57,676 & $12 \%$ & NA & NA & NA & NA & NA & NA & NA & NA \\
\hline & intergenic & 57,740 & $4 \%$ & 57,699 & $9 \%$ & NA & NA & NA & NA & NA & NA & NA & NA \\
\hline & intergenic & 57,745 & $5 \%$ & 57,704 & $9 \%$ & NA & NA & NA & NA & NA & NA & NA & NA \\
\hline & intergenic & 57,892 & $4 \%$ & 57,854 & $8 \%$ & NA & NA & NA & NA & NA & NA & NA & NA \\
\hline & intergenic & 57,897 & $2 \%$ & 57,859 & $13 \%$ & NA & NA & NA & NA & NA & NA & NA & NA \\
\hline
\end{tabular}

C? information about editing not available

a) Editing rate did not achieve the threshold in most plants (using GSNAP or ChloroSeq),

but editing events observed across all 12 individuals of S. vulgaris KO and KRA

)$^{\mathrm{b}}$ GCA triplet in Arabidopsis encoding alanine

)$^{c}$ TCG triplet in Nicotiana, encoding serine

)$^{\mathrm{d}}$ TCA triplet in Vigna, encoding serine

according to this study. As the position 50 of $p s b Z$ is completely edited in the model plant $A$. thaliana, the identification of nuclear factors responsible for the $p s b Z$ editing will be possible, which may help to clarify the function of this editing event.

\section{Antisense RNAs in plastid transcriptomes of S. vulgaris}

We found the long antisense transcript of the $p s b N$ gene, which was more abundant than the sense transcript of this gene. The $p s b N$ gene is located on the strand complementary to the $p s b T-p s b H$ intergenic region, which is a part of the conserved $p s b B$ operon. The transcription of the $p s b N$ gene in A. thaliana is controlled by a specific promoter recognized by the plastid-encoded RNA polymerase together with nucleus-encoded sigma factor SIG3 [42]. The antisense $p s b N$ transcript was found to affect the cleavage of the $p s b T-p s b H$ intercistronic RNA [43] and to influence the translation of $p s b T$ mRNA in A. thaliana [44]. It is therefore possible that antisense $p s b N$ transcript has a similar regulatory function in S. vulgaris. On the contrary, we found only a very low or zero coverage of the strand complementary to the $n d h B$ gene. The antisense $n d h B$ transcript was observed in $A$. thaliana, tobacco and poplar and may play a role in mRNA stability control [45]. Its expression is influenced by temperature and developmental stage. It may not be expressed in floral buds, or in $S$. vulgaris at all.

We did not estimate the expression of small RNAs including tRNAs, owing to a size limitation, but we detected longer antisense RNAs transcribed from the strand complementary to the trn genes. The antisense trnS-GGA and antisense trnW-CCA are located in 3'UTR of rps4 and pet $G$, respectively. They form secondary structures, which may be recognized by RNA-binding proteins that regulate

Table 4 Plastid DNA insertions in mitochondrial genomes of S. vulgaris KRA and S. vulgaris KOV with more than $95 \%$ of sequence similarity

\begin{tabular}{|c|c|c|c|c|c|}
\hline \multicolumn{3}{|l|}{ S.vulgaris KRA } & \multicolumn{3}{|l|}{ S. vulgaris KOV } \\
\hline $\begin{array}{l}\text { Mitochondrial } \\
\text { KRA-1 coordinates }\end{array}$ & $\begin{array}{l}\text { Plastid genome } \\
\text { coordinates }\end{array}$ & $\begin{array}{l}\text { Size } \\
\text { (nt) }\end{array}$ & $\begin{array}{l}\text { Mitochondrial } \\
\text { KOV-1 coordinates }\end{array}$ & $\begin{array}{l}\text { Plastid genome } \\
\text { coordinates }\end{array}$ & $\begin{array}{l}\text { Size } \\
(n t)\end{array}$ \\
\hline$\overline{100,495-100,872}$ & $35,346-35,723$ & 377 & $196,739-203,697$ & $71,340-78,306$ & 6966 \\
\hline $295,098-295,716$ & $40,335-40,982$ & 647 & $189,999-195,890$ & $85,338-91,246$ & 5908 \\
\hline $368,306-371,081$ & $50,900-53,664$ & 2764 & $156,787-169,357$ & $93,157-105,727$ & 12,570 \\
\hline $135,024-135,444$ & $73,826-74,243$ & 417 & & & \\
\hline $318,767-321,559$ & $75,549-78,345$ & 2796 & & & \\
\hline $78,752-79,770$ & $81,520-82,538$ & 1018 & & & \\
\hline
\end{tabular}


transcription of plastid mRNAs [46, 47]. Similarly, the antisense trnS-UGA may stabilize the 5'end of the $p s b Z$ transcript and influence its translation.

Numerous antisense RNAs were described in plastid transcriptomes, for example 107 putative antisense transcripts in A. thaliana [48], or 137 antisense candidates in Salvia miltiorrhiza [49]. We detected only eight putative long antisense RNAs in S. vulgaris, which might have been caused by two factors. First, we narrowed our search by raising the coverage threshold to the level of protein-coding genes. Second, we carefully eliminated reads derived from plastid inserts in the mitochondrial genome, which can be erroneously recognized as plastidencoded transcripts.

The accumulation of antisense RNA can be influenced by the environment and developmental stage [44, 45], which may explain, why some antisense RNAs were expressed only in one haplotype of $S$. vulgaris. On the other hand, all the putative antisense RNAs recognized in the $S$. vulgaris transcriptomes were also found in $A$. thaliana [48], which suggests their evolutionary conservation and possible functional importance.

\section{Conclusions}

We found no significant differences between $\mathrm{F}$ and $\mathrm{H}$ individuals in the plastid transcriptomes prepared from flower buds (where differences between both sexes may be expected) of two haplotypes of gynodioecious plant $S$. vulgaris KRA and KOV, which suggests that CMS was not associated with the changes in plastid gene expression in this species. However, we cannot exclude, that differences in plastid transcriptomes exist in specific tissues of floral buds. We observed differences between the two haplotypes of $S$. vulgaris in the rate of RNA editing of position $50 \mathrm{psbZ}$ gene, which is edited in some angiosperms including $A$. thaliana, but not in the others. Differences in the levels of expression of antisense transcripts were also detected among haplotypes. Our results document the variation in plastid transcriptomes at the intraspecific level in S. vulgaris.

The plastid haplotypes KRA and KOV, from which the transcriptomes were constructed belong to a main cluster in the phylogenetic tree constructed of complete plastid genome sequences. S. vulgaris populations collected in the high European mountains, for which complete plastid genomes were sequenced, were added to phylogenetic analyses to increase intraspecific sampling. They occupy basal positions on the phylogram and may be closer to the ancestor of $S$. vulgaris.

\section{Methods}

\section{Plant material}

We collected seeds of $S$. vulgaris from two populations occurring above a timber line in European mountains
(Dachstein and Vřesová studánka, the haplotypes D11 and VS1, respectively), and from one population growing in sand dunes just above sea level in Netherlands (Zandvoort, ZE2) (Table 1). The mountain populations $S$. vulgaris exhibited morphological traits (floral color, leaf shape, procumbent growth) distinct from lowland plants. These populations were sometimes treated as the separate subspecies $S$. vulgaris subsp. prostrata or S. vulgaris subsp. glareosa [50], but unrestricted gene flow and clinal variation in floral color and flavonoid production along altitudinal gradient were documented [20,33]. We therefore refer to the mountain populations simply as $S$. vulgaris in our study.

Seeds were germinated and cultivated in the greenhouse at the Institute of Experimental Botany (IEB) in Prague, as described previously [19]. S. vulgaris collected in Dachstein is procumbent with light violet flowers. It was sometimes classified as $S$. vulgaris subsp. prostrata [50]. However, individuals with intermediate phenotypes between higher altitude and lower altitude plants were reported [20], which suggests unlimited gene flow among the populations. The Dachstein plants are very sensitive to moisture, and they grew poorly in the greenhouse. Thus they were cultivated under controlled conditions in IEB cultivation rooms at $21^{\circ} \mathrm{C}, 16 / 8 \mathrm{~h}$ light/ dark, in pots filled with perlite, vermiculite, and coconut coir (1:1:1), fertilized (Kristalon-start and Kristalon-fruit and flower, 1: 1) once per week or every second week. The plant material was determined by Helena Štorchová. Seed of each $S$. vulgaris haplotype are deposited at IEB in Prague and are available upon request. All samples collected and used in this study did not require any special permission. Plant materials used in the current research complied with government regulations.

\section{Complete plastid genomic sequences from S. vulgaris D11, VS1, and ZE2}

We performed de novo assembly of three plastid haplotypes of S. vulgaris. About $100 \mathrm{mg}$ of young flower buds from a single $\mathrm{H}$ individual $S$. vulgaris D11, VS1 or ZE2 (Table 2) were flash frozen in liquid nitrogen and ground with a china pestle and mortar in Lysis buffer (Qiagen Genomic DNA Buffer Set). The protocol for the preparation of high-molecular genomic DNA using Qiagen Genomic Tip (20G) was followed according to the manufacturer's instructions. About $8 \mu \mathrm{g}$ of DNA dissolved in $100 \mu \mathrm{l}$ of $10 \mu \mathrm{M}$ Tris- $\mathrm{HCl}$ buffer $(\mathrm{pH}=8.3$ ) was sent to GATC Biotech (Konstanz, Germany) for SMRT sequencing on the Pacific Bioscience RSII P. A similar aliquot of genomic DNA from each of the three accessions of $S$. vulgaris was sent to the Centre of Plant Structural and Functional Genomics IEB in Olomouc for Illumina MiSeq sequencing $(2 \times 300$ cycles, fragment size about $1000 \mathrm{nt})$ using Nextera chemistry for DNA library preparation. 
The SMRT sequencing generated around 39,000 reads with N50 Read length $=16,500$ nt for S. vulgaris D11; 98, 000 reads with N50 Read length $=16,800$ nt for $S$. vulgaris VS1; 94,000 reads with N50 Read length $=18,100 \mathrm{nt}$ for $S$. vulgaris ZE2. A hybrid correction pipeline proovread [51] was adopted to correct long but error-prone SMRT reads with short but accurate MiSeq reads. The proovread output 'trimmed' consisting of error corrected reads was used as a local blast database and the reads homologous to the S. vulgaris plastid genome (JF715057) were identified by blastn search with a cutoff e - 20. Canu v 1.3 [52] was applied for the assembly of proovread corrected reads. The resulting two contigs corresponded to a long single copy region (LSC) plus inverted repeat (IR), and a short single copy region (SSC). The complete plastid genomic sequences were deposited under the Genbank accession numbers MK473866-8 (ZE2, VS1, D11).

The complete plastid genomic sequence JF715057 [15] derived from $S$. vulgaris carrying the mitochondrial haplotype SD2 [16] served as a reference for the annotation of the newly assembled plastid genomes of $S$. vulgaris.

\section{Complete plastid genomic sequences from S. vulgaris KOV and KRA}

The data sets obtained from the Roche 454 GS-FLX platform with Titanium reagents (from constructed $3 \mathrm{~kb}$ paired-end libraries) previously used to assemble mitochondrial genomes of the $S$. vulgaris haplotypes KOV [16] and KRA [18] were utilized for the generation of plastid sequences for both haplotypes. Although the DNA specimens were enriched for mitochondrial DNA, they contained plenty of plastid reads, which provided $10-20 \times$ coverage of the plastid genome. Roche's GS de novo Assembler v.2.6 ('Newbler') was used for initial assembly. The resulting contigs were mapped against the available chloroplast genome of $S$. vulgaris (JF715057) and gaps were filled by individual trimmed 454 reads mapping against the same reference. The KOV and KRA plastid genomic sequences were confirmed by remapping of the 454 reads against them. Alignments were manually checked for potential SNPs, indels and insertions and edited respectively. Within-individual variation in $\mathrm{A}$ or $\mathrm{T}$ homopolymers $>5$ was often observed, which might reflect possible heteroplasmy, or the co-existence of two or more variant sequences in the same individual. The resulting KOV and KRA complete plastid sequences (GenBank accession numbers MH890612 and MH890613) were used as the reference genomes for the following transcriptomic analyses.

\section{Chloroplast genome features}

The distance matrix with the pairwise comparison of single nucleotide polymorphisms across all different plastid genomes was calculated using snp-dists (v. 0.6, github.com/tseemann/snp-dists), while for the pairwise comparison of indels the dist.dna function of the ape package within $\mathrm{R}$ was employed with the "indel" and "indelblock" model. The positions of simple sequence repeats (SSR) were estimated using the microsatellite identification software tool MISA-web [53] with thresholds of the repeat sequence length longer than five nucleotides for mononucleotides, four repeat units for dimer and trinucleotide SSRs, and three repeat units for tetra-, penta- and hexanucleotide SSRs. The genes and coding regions were annotated according to the plastid genome of S. vulgaris (JF715057) and validated by the package ReFernment [54], which confirmed the presence of editing sites in start and stop codons.

\section{Phylogenetic analyses}

First, the six plastid genomes of $S$. vulgaris together with Silene latifolia as outgroup (JF715055) were aligned with MAFFT v.7.388 [55] using the L-INS-i mode with misaligned sites manually edited. The inverted repeat region A (IRA) region was cut from the resulting nucleotide alignment. For the calculation of phylogenetic trees two different alignments were compared; first with noninformative sites such as homopolymer regions masked when longer than five nucleotides in non-coding sequence (CDS); second with CDS only (without tRNAs and rRNAs). Additionally, indel characters were coded using the "simple indel coding" algorithm as described in [56] for both alignments with 2matrix [57]. The phylogenetic trees were calculated using RAxML [58] and MrBayes [59] at the CIPRES portal [60].

The maximum likelihood (ML) method was applied using the CIPRES webportal with RAxML v. 8.2.10 with 1000 bootstraps and the GTRGAMMA model for both bootstrapping and tree inference. Indels were given in a partition file as binary characters describing indel size and distribution throughout the respective sequence alignment. Alternatively, the Bayesian approach for phylogenetic tree construction was employed through MrBayes v. 3.2.6 [59] using the Markov chain Monte Carlo algorithm and the default model 4by4 for 5000 generations in two runs with trees sampled every 1000 generations. The different partitioned nexus file consisted of the sequence alignment and the indel coding, each. Stationary character frequency was fixed for the indel data set and dirichlet $(1.0,1.0,1.0,1.0)$ and the first $25 \%$ of topologies were discarded (burnt in). The analysis was stopped when the standard deviation of split frequencies between the runs was lower than 0.01 .

The numbers of synonymous and nonsynonymous substitutions within $S$. vulgaris plastid protein coding genes were determined with DnaSP v5 [61]. The segregating site was identified, if an alternative nucleotide was found in the respective position in at least one of six aligned plastid sequences of $S$. vulgaris. 


\section{Illumina read mapping}

We used the reads stored under the Short Read Archive accession number PRJNA321915. They were obtained by Illumina sequencing of cDNA derived from total RNA extracted from flower buds of three $\mathrm{F}$ and three $\mathrm{H}$ individuals of S. vulgaris KRA [18] (GenBank accession numbers SRX3102769 - SRX3102774) and from flower buds of three $\mathrm{F}$ and three $\mathrm{H}$ individuals of $S$. vulgaris KOV [19] (GenBank accession numbers SRX272140 - SRX272145).

The initial alignment was performed with the assembler GSNAP v. 2017-05-03 [62] in paired-end mode with known splice sites [14]. The plastid genome sequences of the haplotypes KOV and KRA of S. vulgaris were used as the references. IRA within the reference plastid genome was cut away to ensure proper read mapping with GSNAP. The resulting alignments were separated by strand using the view function in SAMtools v. 1.9 [63] by filtering according to read-pair orientation utilizing SAM flags as described in [18] These alignments were filtered for potential mitochondrial reads derived from plastid DNA inserted to the mitochondrial genome of the corresponding haplotype (GenBank accession numbers JQ771300 and MH455602) (Table 4). At these known regions all reads not matching to the reference sequence and not presenting potential RNA editing were filtered deploying SAMtools view function, a custom AWK script and seqtk v. 1.2 (https://github.com/lh3/seqtk) for subsequent analyses. The mapped reads were visualized by means of the Integrative Genomic Viewer (IGV) [64].

For comparison we also used the ChloroSeq pipeline [25] to analyze the plastid transcriptomes of $S$. vulgaris $\mathrm{KOV}$ and KRA. This pipeline relies on several different, opensource bioinformatic programs, such as SAMtools and BEDtools v. 2.25.0 to run properly. The same reference, known splice sites and filtered reads as for the final GSNAP alignments were used with bowtie v. 2.2.6 [65] and tophat v. 2.1.1 [66] for read mapping as described in [25].

\section{RNA editing rates}

Initial variant discovery was performed with HaplotypeCaller in GenomeAnalysisTK v. 3.7 [67] on the minus- and plusstranded alignments of $S$. vulgaris KOV and KRA with the minimum call and emit threshold (stand_call_conf) set to 20 . All variant sites with C-to- $\mathrm{T}$ for the plus- and G-to-A alteration in the minus-strand were manually checked and verified for subsequent final calling of variants with SAMtools v. 1.2 mpileup using the DPR output tag (discontinued since v. 1.3) for the number of high-quality bases per observed allele. In cases of low read mapping, but definite RNA editing the DP4 values were used to evaluate editing rates across all individuals. RNA editing rates were calculated based on these values as counts of Ts divided by the sum of Cs and Ts at the specific editing sites. The final editing sites were used as list for calculation of editing rates with ChloroSeq. Editing rates below a threshold of $5 \%$ (or 10 edited nucleotides, whatever is smaller), or low coverage (less than 200 reads mapped) are not shown in the final results.

\section{Transcript abundance estimation}

The estimation of transcript abundance was done as described in [19] using the coverage function within bedtools and a custom AWK script. The coverage was calculated per-base, averaged over the length of the respective feature of interest, first regardless of strand followed by strandspecific calculations for each sample and normalized as TPM as described in [68]. The average and standard deviation of TPM were calculated for both haplotypes and sexes. Antisense transcripts were recognized if their depth of coverage exceeded 300-500, which corresponded to the TPM values of the least expressed protein coding genes. The web tool Morpheus (https://software.broadinstitute. org/morpheus) was used for heat map construction.

\section{Supplementary information}

Supplementary information accompanies this paper at https://doi.org/10. 1186/s12870-019-2193-0.

Additional file 1. Numerical tables. Data Set S1. Simple sequence repeats in plastid genomes of S. vulgaris. Data Set S2. Substitution rates in plastid genes of S. vulgaris. Data Set S3. KaKs matrices. Data Set S4. Gene coverage of plastid genes of S. vulgaris. Data Set S5. Antisense transcript coverage in plastid genomes of S. vulgaris. Data Set S6. Editing rates in plastid genomes of S. vulgaris. Data Set S7. psbZ editing extent

Additional file 2: Figure S1. Maximum likelihood phylogenetic trees for different plastid haplotypes of Silene vulgaris. a. based on all sites of the plastid genome except for homopolymer sites larger than five nucleotides; b. plastid coding regions only. Silene latifolia was used as outgroup. Long branches were shorten by $50 \%$, indicated with two diagonal slashes. Indels were coded after Simmon \& Ochoterena (2000). The scale bar indicates the number of substitutions per site. Branches with bootstrap support below $60 \%$ were collapsed to polytomies. Phylogenetic trees were computed through the CIPRES webportal with RAxML v. 8.2.10 using 1000 bootstraps and the GTRGAMMA model

Additional file 3: Figure S2. Bayesian 50\% majority rule phylogenetic trees for different plastid haplotypes of Silene vulgaris based on a. all sites of the plastid genome except homopolymer regions larger than five nucleotides; b. plastid coding regions only; c. all sites of the plastid genome except homopolymer regions larger than five nucleotides with simple indel coding after Simmon \& Ochoterena (2000); d. plastid coding regions only with simple indel coding. Silene latifolia was used as outgroup. Long branches were shorten by $50 \%$, indicated with two diagonal slashes. The scale bar indicates the number of substitutions per site. Phylogenetic trees were computed through the CIPRES webportal with MrBayes v. 3.2.6 using 5000 generations

Additional file 4: Figure $\mathbf{S 3}$ Heat maps showing the transcript levels of the plastid ndh genes across six individuals of S. vulgaris KRA and KOV. The $n d h F$ gene is the least expressed gene in both haplotypes, the expression of the other genes varies between the two haplotypes

Additional file 5: Figure S4. The comparison of editing rates estimated by the GSNAP and the ChloroSeq pipeline. Mean values $( \pm$ SD) calculated from six individuals are plotted, a 95\% confidence band for the observed data is given in gray within plot

\section{Abbreviations}

accD: acetyl-CoA carboxylase subunit D; bp: base pair; CDNA: complementary DNA; CMS: Cytoplasmic male sterility; F: Female; H: hermaphrodite; 
kb: kilobase; LSC: Long single copy; matK: maturase K; ndhA: NADH dehydrogenase $A ;$ ndhB: NADH dehydrogenase $B ;$ indhD: NADH dehydrogenase D; ndhF: NADH dehydrogenase F; psbA: photosystem II protein $A$; psbE: photosystem II protein $E_{i}$ psbH: photosystem II protein $\mathrm{H}_{\text {; }}$ psbN: photosystem II protein N; psbT: photosystem II protein $T_{\text {; }}$ psbZ: photosystem II protein Z; rbcL: rubisco subunit L; rpoB: RNA polymerase B; rps 14: ribosomal protein S14; rps 16: ribosomal protein S16; rRNA: ribosomal RNA; SSC: Short single copy; SSR: Simple sequence repeat; tRNA: transfer RNA; UTR: Untranslated region

\section{Acknowledgements}

The authors thank Dan B. Sloan and James D. Stone for valuable comments and linguistic corrections. We are grateful to Miroslav Valárik of Olomouc for MiSeq sequencing. Access to computing and storage facilities owned by parties and projects contributing to the National Grid Infrastructure MetaCentrum, provided under the programme "Projects of Large Infrastructure for Research, Development, and Innovations" (LM2010005), is greatly appreciated.

\section{Authors' contributions}

MK performed most data analyzes and interpretations, MJ participated in data analyzes, OAJA and CK performed wet lab work, HŠ conceived and designed the experiments and provided interpretation, $\mathrm{HS}$ and MK wrote the manuscript. All authors read and approved the final manuscript.

\section{Funding}

This project was funded by the grant of the Grant Agency of the Czech Republic 16-09220S to HŠ. Additional support was provided by European Regional Development Fund-Project "Centre for Experimental Plant Biology" (No. CZ.02.1.01/0.0/0.0/16_019/0000738). Funders provided financial support only, they had no role in the design of the study, analysis and interpretation of data, decision to publish, or the preparation of the manuscript

\section{Availability of data and materials}

The data of this study data have been deposited in the NCBI with BioProject accession number PRJNA321915. The RNA-seq reads from hermaphrodites of S. vulgaris KRA are stored under the number SRS2438489, the reads from females under the number SRS2438490. The RNA-seq reads from six individuals of S. vulgaris KRA are deposited under GenBank accession numbers SRX272140 - SRX272145. The complete plastid genomes can be found under GenBank accession numbers MH890612 and MH890613 (KOV and KRA), and MK473866-8 (ZE2, VS1,D11).

\section{Ethics approval and consent to participate} Not applicable.

\section{Consent for publication}

Not applicable.

\section{Competing interests}

The corresponding author [Helena Storchova] is a member of the editorial board of BMC Plant Biology, the authors declare that they have no other competing interests.

Received: 2 July 2019 Accepted: 10 December 2019 Published online: 19 December 2019

\section{References}

1. Renner SS. The relative and absolute frequencies of angiosperm sexual systems: Dioecy, monoecy, gynodioecy, and an updated online database. Am J Bot. 2014;101:1588-96. https://doi.org/10.3732/ajb.1400196.

2. Hanson MR, Bentolila S. Interactions of mitochondrial and nuclear genes that affect male gametophyte development. Plant Cell. 2004;16:S154-69. https://doi.org/10.1105/tpc.015966.

3. Kazama T. Nakamura, Watanabe, M. Sugita KT. Suppression mechanism of mitochondrial ORF79 accumulation by Rf1 protein in BT-type cytoplasmic male sterile rice. Plant J. 2008;55:619-28. https://doi.org/10.1111/j.1365-313X.2008.03529x.

4. Wang K, Gao F, Ji Y, Liu Y, Dan Z, Yang P, et al. ORFH79 impairs mitochondrial function via interaction with a subunit of electron transport chain complex III in Honglian cytoplasmic male sterile rice. New Phytol. 2013;198:408-18. https://doi.org/10.1111/nph.12180.
5. Sabar M, Gagliardi D, Balk J, Leaver C. ORFB is a subunit of F1FO-ATP synthase: insight into the basis of cytoplasmic male sterility in sunflower. EMBO Rep. 2003;4:381-6. https://doi.org/10.1038/sj.embor.embor800.

6. Allen JO, Fauron CM, Minx P, Roark L, Oddiraju S, Guan NL, et al. Comparisons among two fertile and three male-sterile mitochondrial genomes of maize. Genetics. 2007;177:1173-92. https:/doi.org/10.1534/genetics.107.073312.

7. Darracq A, Varré JS, Maréchal-Drouard L, Courseaux A, Castric V, SaumitouLaprade P, et al. Structural and content diversity of mitochondrial genome in beet: a comparative genomic analysis. Genome Biol Evol. 2011;3:723-36. https://doi.org/10.1093/gbe/evr042.

8. Charlesworth D, Laporte V. The male-sterility polymorphism of Silene vulgaris: analysis of genetic data: from two populations and comparison with Thymus vulgaris. Genetics. 1998;150:1267-82.

9. Desfeux C, Maurice S, Henry JP, Lejeune B, Gouyon PH. Reproductive Systems in the Genus Silene. Evolution of reproductive systems in the genus Silene. Proc R Soc B Biol Sci. 1996;263:409-14.

10. Casimiro-Soriguer I, Buide ML, Narbona E. Diversity of sexual systems within different lineages of the genus Silene. AOB Plants. 2015;7:plv037. doi:https:// doi.org/10.1093/aobpla/plv037

11. Städler T, Delph LF. Ancient mitochondrial haplotypes and evidence for intragenic recombination in a gynodioecious plant. Proc Natl Acad Sci U S A. 2002;99:11730-5. https://doi.org/10.1073/pnas.182267799.

12. Touzet $P$, Delph LF. The effect of breeding system on polymorphism in mitochondrial genes of silene. Genetics. 2009;181:631-44. https://doi.org/10. 1534/genetics.108.092411.

13. Mower JP, Touzet P, Gummow JS, Delph LF, Palmer JD. Extensive variation in synonymous substitution rates in mitochondrial genes of seed plants. BMC Evol Biol. 2007;7:7. https://doi.org/10.1186/1471-2148-7-135.

14. Sloan DB, Alverson AJ, Chuckalovcak JP, Wu M, McCauley DE, Palmer JD, et al. Rapid evolution of enormous, multichromosomal genomes in flowering plant mitochondria with exceptionally high mutation rates. PLoS Biol. 2012;10: e1001241. doi:0.1371/journal.pbio.1001241.

15. Sloan DB, Alverson AJ, Wu M, Palmer JD, Taylor DR. Recent acceleration of plastid sequence and structural evolution coincides with extreme mitochondrial divergence in the angiosperm genus Silene. Genome Biol Evol. 2012;4:294-306. https://doi.org/10.1093/gbe/evs006.

16. Sloan DB, Müller K, McCauley DE, Taylor DR, Storchová H. Intraspecific variation in mitochondrial genome sequence, structure, and gene content in Silene vulgaris, an angiosperm with pervasive cytoplasmic male sterility. New Phytol. 2012;196:1228-39. https://doi.org/10.1111/j.1469-8137.2012.04340.x.

17. Sloan DB, Triant DA, Forrester NJ, Bergner LM, Wu M, Taylor DR. A recurring syndrome of accelerated plastid genome evolution in the angiosperm tribe Sileneae (Caryophyllaceae). Mol Phylogenet Evol. 2014;72:82-9. https://doi. org/10.1016/j.ympev.2013.12.004.

18. Štorchová H, Stone JD, Sloan DB, Abeyawardana OA, Muller K, Walterová J, Pažoutová M. Homologous recombination changes the context of cytochrome b transcription in the mitochondrial genome of Silene vulgaris KRA. BMC Genomics. 2018;19:874. https://doi.org/10.1186/s12864-018-5254-0.

19. Stone JD, Koloušková P, Sloan DB, Štorchová H. Non-coding RNA may be associated with cytoplasmic male sterility in Silene vulgaris. J Exp Bot. 2017; 68:1599-612. https://doi.org/10.1093/jxb/erx057.

20. Abbate $J$, Antonovics J. Elevational disease distribution in a natural plantpathogen system: insights from changes across host populations and climate. Oikos. 2014;123:1126-36. https://doi.org/10.1111/oik.01001.

21. Li ZF, Zhang YC, Chen YQ. MiRNAs and IncRNAs in reproductive development. Plant Sci. 2015;238:46-52. https://doi.org/10.1016/j.plantsci.2015.05.017.

22. Wu J, Zhang M, Zhang B, Zhang X, Guo L, Qi T, et al. Genome-wide comparative transcriptome analysis of CMS-D2 and its maintainer and restorer lines in upland cotton. BMC Genomics. 2017;18:454. https://doi.org/ 10.1186/s12864-017-3841-0.

23. Hamid R, Tomar RS, Marashi H, Malekzadeh S, Golakiya BA, Mohsenpour M. Transcriptome profiling and cataloging differential gene expression in floral buds of fertile and sterile lines of cotton (Gossypium hirsutum L.). Gene. 2018;660:80-91. https://doi.org/10.1016/j.gene.2018.03.070.

24. Plöchinger M, Schwenkert S, von Sydow L, Schroder WP, Meurer J. Functional update of the auxiliary TerC and ALB3 in maintenance and assembly of PSII. Front Plant Sci. 2016;7:423. https://doi.org/10.3389/fpls.2016.00423.

25. Castandet B, Hotto AM, Strickler SR, Stern DB. ChloroSeq, an optimized chloroplast RNA-Seq bioinformatic pipeline, reveals Remodeling of the organellar transcriptome under heat stress. G3-Genes Genomes Genet. 2016; 6:2817-27. https://doi.org/10.1534/g3.116.030783. 
26. Hein A, Polsakiewicz M, Knoop V. Frequent chloroplast RNA editing in earlybranching flowering plants: pilot studies on angiosperm-wide coexistence of editing sites and their nuclear specificity factors. BMC Evol Biol. 2016;16: 23. https://doi.org/10.1186/s12862-016-0589-0.

27. Wang W, Zhang W, Wu Y, Maliga P, Messing J. RNA editing in chloroplasts of Spirodela polyrhiza, an aquatic monocotelydonous species. PLoS One. 2015;10:e0140285. https://doi.org/10.1371/journal.pone.0140285.

28. Wang M, Liu H, Ge L, Xing G, Wang M, Weining S, et al. Identification and analysis of RNA editing sites in the chloroplast transcripts of Aegilops tauschii L. Genes. 2017;8:13. https://doi.org/10.3390/genes8010013.

29. Ruwe H, Castandet B, Schmitz-Linneweber C, Stern DB. Arabidopsis chloroplast quantitative editotype. FEBS Lett. 2013;587:1429-33. https://doi. org/10.1016/j.febslet.2013.03.022.

30. Tangphatsornruang S, Uthaipaisanwong P, Sangsrakru D, Chanprasert J, Yoocha T, Jomchai $\mathrm{N}$, et al. Characterization of the complete chloroplast genome of Hevea brasiliensis reveals genome rearrangement, RNA editing sites and phylogenetic relationships. Gene. 2011;475:104-12. https:/doi.org/10.1016/j.gene.2011.01.002.

31. Hirose T, Kusumegi T, Tsudzuki T, Sugiura M. RNA editing sites in tobacco chloroplast transcripts : editing as a possible regulator of chloroplast RNA polymerase activity. Mol Gen Genet. 1999;262:462-7.

32. Lin C, Ko C, Kuo C, Liu M, Schafleitner R. Transcriptional slippage and RNA editing increase the diversity of transcripts in chloroplasts : insight from deep sequencing of Vigna radiata genome and transcriptome. PLoS One. 2015;10:e0129396. https://doi.org/10.1371/journal.pone.0129396.

33. Berardi AE, Fields PD, Abbate JL, Taylor DR. Elevational divergence and clinal variation in floral color and leaf chemistry in Silene vulgaris. Am J Bot. 2016; 103:1508-23. https://doi.org/10.3732/ajb.1600106.

34. Tseng CC, Lee CJ, Chung YT, Sung TY, Hsieh MH. Differential regulation of Arabidopsis plastid gene expression and RNA editing in non-photosynthetic tissues. Plant Mol Biol. 2013;82:375-92. https://doi.org/10.1007/s11103-013-0069-5.

35. Maier RM, Neckermann K, Igloi GL, Kossel H. Complete sequence of the maize chloroplast genome: gene content, hotspots of divergence and fine tuning of genetic information by transcript editing. J Mol Biol. 1995;251:614-28.

36. Sloan DB. Nuclear and mitochondrial RNA editing systems have opposite effects on protein diversity. Biol Lett. 2017;13:20170314. https://doi.org/10. 1098/rsbl.2017.0314.

37. Kahlau S, Bock R. Plastid transcriptomics and translatomics of tomato fruit development and chloroplast-to-chromoplast differentiation : chromoplast gene expression largely serves the production of a single protein. Plant Cell. 2008;20:856-74. https://doi.org/10.1105/tpc.107.055202.

38. Valkov VT, Scotti N, Kahlau S, Maclean D, Grillo S, Gray JC, et al. Genomewide analysis of plastid gene expression in potato leaf chloroplasts and tuber amyloplasts: transcriptional and posttranscriptional control. Plant Physiol. 2009;150:2030-44. https://doi.org/10.1104/pp.109.140483.

39. Swiatek M, Kuras R, Sokolenko A, Higgs D, Olive J, Cinque G, et al. The chloroplast gene ycf9 encodes a photosystem II ( PSII ) core subunit, PsbZ, that participates in PSII supramolecular architecture. Plant Cell. 2001;13:1347-67.

40. Wei $X$, Su X, Cao P, Liu X, Chang W, Li M, et al. Structure of spinach photosystem II - LHCII supercomplex at $3.2 \AA$ resolution. Nature. 2016;534 69-74. https://doi.org/10.1038/nature18020.

41. Kawabe A, Furihata HY, Tsujino Y, Kawanabe T, Fujii S, Yoshida T. Divergence of RNA editing among Arabidopsis species. Plant Sci. 2019;280:241-7. https://doi.org/10.1016/j.plantsci.2018.12.009

42. Zghidi W, Merendino L, Cottet A, Mache R, Lerbs-Mache S. Nucleus-encoded plastid sigma factor SIG3 transcribes specifically the $p s b N$ gene in plastids. Nucleic Acids Res. 2007;35:455-64. https://doi.org/10.1093/nar/gkl1067.

43. Chevalier F, Ghulam MM, Rondet D, Pfannschmidt T, Merendino L, LerbsMache $\mathrm{S}$. Characterization of the $\mathrm{ps} b \mathrm{H}$ precursor RNAs reveals a precise endoribonuclease cleavage site in the $p s b T / p s b H$ intergenic region that is dependent on psbN gene expression. Plant Mol Biol. 2015;88:357-67. https://doi.org/10.1007/s11103-015-0325-y.

44. Zghidi-Abouzid O, Merendino L, Buhr F, Ghulam MM, Lerbs-Mache S. Characterization of plastid psbT sense and antisense RNAs. Nucleic Acids Res. 2011;39:5379-87. https://doi.org/10.1093/nar/gkr143.

45. Georg J, Honsel A, Rennenberg H, Hess WR. Rapid report a long antisense RNA in plant chloroplasts. New Phytol. 2010;4:615-22. https://doi.org/10. 1111/j.1469-8137.2010.03203.x.

46. Bollenbach TJ, Sharwood RE, Gutierrez R, Lerbs-Mache S, Stern DB. The RNAbinding proteins CSP41a and CSP41b may regulate transcription and translation of chloroplast-encoded RNAs in Arabidopsis. Plant Mol Biol. 2009; 69:541-52. https://doi.org/10.1007/s11103-008-9436-z.
47. Manavski N, Schmid LM, Meurer J. RNA-stabilization factors in chloroplasts of vascular plants. Essays Biochem. 2018;62:51-64. https:/doi.org/10.1042/EBC20170061.

48. Hotto AM, Schmitz RJ, Fei Z, Ecker JR, Stern DB. Unexpected diversity of chloroplast noncoding RNAs as revealed by deep sequencing of the Arabidopsis transcriptome. G3-Genes Genomes Genet. 2011;1:559-70. https://doi.org/10.1534/g3.111.000752.

49. Chen H, Zhang J, Yuan G, Liu C. Complex interplay among DNA modification, noncoding RNA expression and protein-coding RNA expression in Salvia miltiorrhiza chloroplast genome. PLoS One. 2014;9: e99314. https://doi.org/10.1371/journal.pone.0099314.

50. Marsden-Jones EM, Turrill WB. The bladder campions. London: The Ray Society; 1957.

51. Hackl T, Hedrich R, Schultz J, Forster F. Sequence analysis proovread : largescale high-accuracy PacBio correction through iterative short read consensus. Bioinformatics. 2014:30:3004-11. https://doi.org/10.1093/bioinformatics/btu392.

52. Koren S, Walenz BP, Berlin K, Miller JR, Bergman NH, Phillippy AM. Canu: scalable and accurate long-read assembly via adaptive $\mathrm{k}$-mer weighting and repeat separation. Genome Res. 2017;27:722-36. https:/doi.org/10.1101/gr.215087.116.

53. Beier S, Thiel T, Munich T, Scholz U, Mascher M. Sequence analysis MISAweb: a web server for microsatellite prediction. Bioiformatics. 2017;33:25832585. doi: 0.1093/bioinformatics/btx198.

54. Robison TA, Wolf PG. ReFernment: an R package for annotating RNA editing in plastid genomes. Appl Plant Sci. 2019;7:e1216. https://doi.org/10.1002/aps3.1216.

55. Katoh K, Standley DM. MAFFT multiple sequence alignment software version 7: improvements in performance and usability article fast track. Mol Biol Evol. 2013;30:772-80. https://doi.org/10.1093/molbev/mst010.

56. Simmons MP, Ochoterena H. Society of Systematic Biologists gaps as characters in sequence-based phylogenetic analyses. Syst Biol. 2000;49:369-81.

57. Salinas DR, Little DP. 2MATRIX : A utility for indel coding and phylogenetic MATRIX concatenation. Appl Plant Sci. 2014;2:1300083. https://doi.org/10. 3732/apps.1300083.

58. Stamatakis A. RAXML version 8 : a tool for phylogenetic analysis and postanalysis of large phylogenies. Bioinformatics. 2014;30:1312-3. https://doi.org/ 10.1093/bioinformatics/btu033.

59. Ronquist F, Teslenko M, van der Mark P, Ayres DL, Darling A, Hohna S, et al. MrBayes 3.2: efficient bayesian phylogenetic inference and model choice across a large model space. Syst Biol. 2012;61:539-42. https:/doi.org/10.1093/sysbio/sys029.

60. Miller MA, Pfeiffer W, Schwartz T. Creating the CIPRES Science Gateway for inference of large phylogenetic trees. Proceedings of the Gateway Computing Environments Workshop (GCE), 14 Nov. 2010, New Orleans. LA: IEEE; p 1-8. https://doi.org/10.1109/GCE.2010.5676129.

61. Librado P, Rozas J. DnaSP v5: a software for comprehensive analysis of DNA polymorphism data. Bioinformatics. 2009;25:1451-2. https://doi.org/10.1093/ bioinformatics/btp187.

62. Wu TD, Nacu S. Fast and SNP-tolerant detection of complex variants and splicing in short reads. Bioinformatics. 2010;26:873-81. https://doi.org/10. 1093/bioinformatics/btq057.

63. Li H, Handsaker B, Wysoker A, Fennell T, Ruan J, Homer N, et al. The sequence alignment / map format and SAMtools. Bioinformatics. 2009;25: 2078-9. https://doi.org/10.1093/bioinformatics/btp352.

64. Thorvaldsdottir P. Integrative genomics viewer (IGV): high-performance genomics data visualization and exploration. Brief Bioinform. 2012;14:17892. https://doi.org/10.1093/bib/bbs017.

65. Langmead B, Salzberg SL. Fast gapped-read alignment with bowtie 2. Nat Methods. 2012;9:357-9. https://doi.org/10.1038/nmeth.1923.

66. Trapnell C, Pachter L, Salzberg SL. TopHat : discovering splice junctions with RNA-Seq. Bioinformatics. 2009;25:1105-11. https://doi.org/10.1093/ bioinformatics/btp120

67. McKenna A, Hanna M, Banks E, Sivachenko A, Cibulskis A, Kernytsky A, et al. The genome analysis toolkit: a MapReduce framework for analyzing next-generation DNA sequencing data. Genome Res. 2010;20:1297-303. https:/doi.org/10.1101/gr.107524.110.

68. Wagner GP, Kin K, Lynch VJ. Measurement of mRNA abundance using RNAseq data: RPKM measure is inconsistent among samples. Theory Biosci. 2012;131:281-5. https://doi.org/10.1007/s12064-012-0162-3.

\section{Publisher's Note}

Springer Nature remains neutral with regard to jurisdictional claims in published maps and institutional affiliations. 